\title{
Advancements in the Pharmaceutical Applications of Probiotics: Dosage Forms and Formulation Technology
}

\author{
Kshitis Chandra Baral \\ Rajiv Bajracharya \\ Sang Hoon Lee \\ Hyo-Kyung Han
}

BK2I FOUR Team and Integrated Research Institute for Drug Development, College of Pharmacy, Dongguk University-Seoul, Goyang, 10326, Korea
Correspondence: Hyo-Kyung Han BK2I FOUR Team, College of Pharmacy, Dongguk University-Seoul, Dongguk-ro -32, Ilsan-Donggu, Goyang, 10326, Korea Tel +82-3I-96I-52I7

Fax +82-3I-96I-5206

Email hkhan@dongguk.edu

\begin{abstract}
Probiotics have demonstrated their high potential to treat and/or prevent various diseases including neurodegenerative disorders, cancers, cardiovascular diseases, and inflammatory diseases. Probiotics are also effective against multidrug-resistant pathogens and help maintain a balanced gut microbiota ecosystem. Accordingly, the global market of probiotics is growing rapidly, and research efforts to develop probiotics into therapeutic adjuvants are gaining momentum. However, because probiotics are living microorganisms, many biological and biopharmaceutical barriers limit their clinical application. Probiotics may lose their activity in the harsh gastric conditions of the stomach or in the presence of bile salts. Moreover, they easily lose their viability under thermal or oxidative stress during their preparation and storage. Therefore, stable formulations of probiotics are required to overcome the various physicochemical, biopharmaceutical, and biological barriers and to maximize their therapeutic effectiveness and clinical applicability. This review provides an overview of the pharmaceutical applications of probiotics and covers recent formulation approaches to optimize the delivery of probiotics with particular emphasis on various dosage forms and formulation technologies.
\end{abstract}

Keywords: probiotic, therapeutic adjuvant, formulation, drug delivery system, gut microbiota

\section{Introduction}

Gut microbiota and its composition affect the various physiological processes essential for human health. Thus, disruption in human microbiome (dysbiosis) is associated with many pathological disorders, and the restoration of the intestinal microbiota composition is important to prevent further complications. ${ }^{1-3}$ The qualitative and quantitative compositions of gut microbiota can be altered by various factors including disease states, physical activity, antibiotic therapy and dietary habits. $^{3}$ Various strategies have been developed to maintain the balanced gut microbiome and promote human health, including oral delivery of prebiotics, probiotics, synbiotics, and postbiotics. Among them, probiotics maintain a balanced gut microbiota ecosystem, replenishing the natural gastrointestinal microflora. In addition, since probiotics exhibit a diverse range of biological functions, they are a promising therapeutic adjuvant for the treatment and/or prevention of various diseases including neurodegenerative disorders, cancers, osteoporosis, cardiovascular diseases, and inflammatory diseases. ${ }^{4}$ In recent years, probiotics-based drug delivery systems also gain a great attention since they 
provide additional benefits including the inhibition of cellular adhesion and invasion of pathogenic organisms, antimicrobial activity, and modulation of host immune response. ${ }^{5,6}$ Particularly, they may be an economical and robust way to deliver macromolecules such as recombinant proteins, cytokines, and enzymes. ${ }^{7}$ Therefore, probiotics can not only be used as effective therapeutic adjuvants but also as drug delivery carriers. ${ }^{8}$ Accordingly, the global market of probiotics has expanded continuously and is expected to reach 77.09 billion USD by $2025 .{ }^{8}$ With the increased interest in the clinical application of probiotics, the Food and Drug Administration (FDA) has defined a new "live biotherapeutic products (LBP)" category, to clarify the regulatory status and pharmaceutical expectations. ${ }^{9,10}$ Probiotics can be regulated differently depending on their intended use (dietary supplement or drug). While dietary supplements do not require the approval by FDA, probiotics as LBP that are intended for use in prevention, treatment, or cure of diseases should undergo the regulatory process similar to that of any new therapeutic agent. Regulatory issues on the probiotics are reviewed in details elsewhere. ${ }^{9,10}$

The identification and characterization of therapeutic strains and elucidation of underlying mechanisms of action are hurdle in the development of effective therapeutic probiotics. Furthermore, as probiotics are living microorganisms, they are easily destabilized during their preparation, storage, and in vivo application. Probiotics may lose their activity in the harsh gastric conditions of the stomach or in the presence of bile salts. In addition, various physicochemical and environmental factors during manufacture and storage of probiotics make them nonviable. Therefore, stable formulations of probiotics are required to overcome the various pharmaceutical and biological barriers, maximizing their therapeutic effectiveness and clinical applicability. Various formulation approaches have been adopted to resolve the instability issues of probiotics. Particularly, oral formulations are predominant in current market owing to their advantages including ease of self-medication, low risk of infection, cost-effectiveness, and high patient compliance. Other routes of administration such as nasal, transdermal, vaginal, and rectal administration have been also actively pursued to optimize the therapeutic effectiveness of probiotics, offering alternative platforms for the probiotics delivery. Since each route of administration has its own biological barriers and limitations, formulation strategies should vary depending on the route of administration and more details are discussed in Formulations for the Effective Delivery of Probiotics. Advancements in formulation techniques including micro-/nanoencapsulation facilitate the development of more elaborated formulations with controlled particle size and surface modification, improving the viability and target selectivity of probiotics. Selected examples of recent formulation technologies available for probiotics are covered in Microencapsulation Technology for Probiotics and Nanotechnology for probiotics.

This review provides an overview of the pharmaceutical applications of probiotics. It covers the barriers limiting the clinical application of therapeutic probiotics and recent formulation approaches to optimize the delivery of probiotics with particular emphasis on various dosage forms and formulation technologies.

\section{Limitations in the Pharmaceutical Application of Probiotics}

Before formulation development, it is critical to understand various physicochemical and biological factors that affect the stability and in vivo performance of probiotics. These factors greatly impact the viability of probiotics under environmental stress (oxidation, reduction, humidity, temperature, $\mathrm{pH}$ change), stability in biological fluids, and susceptibility to enzymatic degradation. ${ }^{11,12}$ Therefore, this review provides a brief overview of some of the major factors to be considered in the formulation development for probiotics. However, given that bacteria have also multiple defense mechanisms to counteract intracellular damage and to cope with harmful external environments, the biological and pharmaceutical barriers should be considered in conjunction with various defense mechanisms that aid the survival of probiotics during exposure to various stress conditions. ${ }^{13}$

\section{Biological Factors}

After oral administration, probiotics are exposed to the harsh environment of the gastrointestinal (GI) tract, particularly the stomach and the upper intestine. The highly acidic gastric fluids ( $\mathrm{pH} 1-3)$ and the gastric emptying time of about $2 \mathrm{~h}$ significantly reduce the viability of probiotics in the stomach. ${ }^{14}$ The highly acidic gastric $\mathrm{pH}$ decreases the cytoplasmic $\mathrm{pH}$ and glycolytic enzyme activity of probiotics, affecting the F1Fo-ATPase proton pump that is responsible for the survival of probiotics under acidic conditions. ${ }^{15}$ Thus, acid resistance is a critical factor and desirable attribute of oral probiotic 
delivery systems. High ionic strength, enzyme activity (pepsin), and gastric motility can also reduce the viability of probiotics. ${ }^{15}$

Bile acids and other digestive enzymes including lipases, proteases, and amylases in the small intestine also affect the viability of probiotics. The increased secretion of bile acids in the small intestine, particularly because of the intake of high-fat meals, may create an unfavorable environment for many probiotics. While bile acids facilitate the digestion and absorption of ingested lipids, they exhibit antimicrobial properties by acting as biological detergents that disrupt cell membranes and damage DNA. ${ }^{16}$ Therefore, an increase in bile acid secretion may decrease the viability of probiotics in the small intestine. Similarly, proteolytic enzymes including trypsin and chymotrypsin can cause lysis of some bacterial strains and inhibit their growth. ${ }^{17}$

Although oral administration is the most preferred route of administration for probiotics, the significant instability of probiotics in the GI tract requires formulations for an alternative route of administration. Accordingly, in recent years, formulations bypassing the GI tract have been actively pursued. However, each route of administration has its own limitations. For example, the efficacy of probiotics after vaginal administration can be affected by cervical mucus and the variations in the vaginal microenvironment including the thickness of the vaginal mucosa and properties of the vaginal fluid. ${ }^{18}$ Likewise, the intranasal delivery of probiotics is affected by various factors such as rapid mucociliary clearance, short retention time, small surface area, and enzymatic degradation. ${ }^{19,20}$ In addition, the colonization of probiotic strains on the respiratory epithelium can be affected by the presence of the nasal microbial community. ${ }^{21}$ Therefore, the formulation strategy for the effective delivery of probiotics should vary depending on the biological barriers encountered with each route of administration. This topic has been discussed more in Formulations for the Effective Delivery of Probiotics.

\section{Pharmaceutical Factors}

During manufacturing and storage, probiotics can be exposed to various stress conditions affecting their stability. The main stressors destabilizing probiotics include heat, oxygen level, mechanical force, osmotic shock, and $\mathrm{pH}$ changes. For example, the commonly used process such as spray drying often induce thermal stress and the elevated temperature may denature the proteins and cause cell damage in probiotics. ${ }^{12}$ The drying process can lead to osmotic shock by increasing intracellular osmolarity, which can cause physiological changes in the outer cellular membrane. ${ }^{12}$ Freezing and thawing processes also affect the viability of probiotics. ${ }^{22}$ The mechanical stress imposed by the formation of ice crystals in the media or inside the cells can damage the cell membranes of probiotics during freezing, whereas osmotic stress may further reduce the viability of probiotics during thawing. ${ }^{22}$

Under the hypo- or hypertonic conditions, osmotic shock affects cell viability. Particularly, low osmotic pressure increases the internal pressure of cells due to water absorption, resulting in cell lysis. ${ }^{23}$ Probiotic bacteria also encounter mechanical stress during the formulation process. The compression force during tableting damages the bacterial cell wall and other bio-active components, reducing the survival rate of probiotics. ${ }^{24}$ Shearing force induced by inter-particulate movement also affects the survival rate of probiotic cells. ${ }^{25}$ Similarly, oxidative stress affects the survival of probiotics during manufacture and storage. While oxygen itself is not harmful, the reactive oxygen species, generated by its partial reduction to water, can damage the proteins, lipids, and DNA of probiotics. ${ }^{26}$ Spray-dried cells may be more vulnerable to oxidative stress due to cellular injuries during dehydration. ${ }^{13}$ In addition, the cellular accumulation of toxic oxygen metabolites eventually leads to cell death (referred to as oxygen toxicity). ${ }^{27}$ The ability to withstand oxidative stresses should be important in the selection of probiotic strains.

Although genetic manipulation techniques have been used to enhance the stability of microorganisms under various stresses presented during manufacture and storage, safety remains a concern. Accordingly, protection of probiotics against these stresses should be one of the main objectives of formulation development.

\section{Formulations for the Effective Delivery of Probiotics}

Various formulation approaches have been attempted via different routes of administration to maximize the therapeutic benefits of probiotics as exemplified in Table 1. Each route of administration has its own limitations depending on the anatomical properties, microclimate, and specific physiological conditions. Therefore, formulation strategies can vary with routes of administration, probiotic strains, and therapeutic areas. More details on 
Table I Selected Examples of Probiotic Formulations

\begin{tabular}{|l|c|c|c|}
\hline Probiotics* & Dosage Forms & Route & Reference \\
\hline Enterococcus faecium & Oral film & Oral & {$[35]$} \\
Levilactobacillus brevis & Buccal film & Oral & {$[37]$} \\
Lacticaseibacillus casei & Powder & Oral & {$[42]$} \\
Lactobacillus acidophilus & Granule & Oral & {$[45]$} \\
Limosilactobacillus reuteri & Tablet & Oral & {$[30]$} \\
Lactiplantibacillus plantarum & Orodispersible tablet & Oral & {$[51]$} \\
Lactobacillus strains & Capsule & Oral & {$[48]$} \\
Lactiplantibacillus plantarum & Hydrogel & Oral & {$[56]$} \\
Streptococcus salivarius & Nasal spray & Nasal & {$[68]$} \\
Lacticaseibacillus casei & Nasal spray & Nasal & {$[7 I]$} \\
Lactobacillus & Microneedle & Transdermal & {$[82]$} \\
Lactobacillus subsp. & Tablet & Vaginal & {$[88]$} \\
Lactobacillus gasseri & In-situ gel & Vaginal & {$[90]$} \\
Lactobacillus acidophilus & Suppository & Vaginal & {$[101]$} \\
Limosilactobacillus reuteri & Enema & Rectal & {$[I I]$} \\
\hline
\end{tabular}

Note: *Probiotics names presented in the cited references are updated with the recent taxonomic classification.

the delivery systems of probiotics are discussed in the next section according to the route of administration.

\section{Oral Delivery}

Owing to high patient compliance, cost-effectiveness, and ease of mass production, oral formulations are the most preferred dosage forms of probiotics. Accordingly, oral formulations are most common for prophylactic or therapeutic probiotics, particularly for the treatment of Crohn's disease, ulcerative colitis, and irritable bowel syndrome, maintenance of intestinal microflora after antibiotic therapy, or suppression of tumor growth. ${ }^{28}$ Oral delivery of probiotics can be achieved through diverse dosage forms, including tablets, capsules, oral films, and hydrogels. Microencapsulation and surface coating technologies are also often adopted to enhance the stability of probiotics in the GI tract. Various protein-based bio-polymers, polysaccharides, lipids, and synthetic polymers have been used for microencapsulation or surface coating to make the formulation resist harsh environmental conditions. ${ }^{29}$ These polymers can protect probiotics from moistures or gases (oxygen/ carbon dioxide) by masking them with a thin film. Furthermore, $\mathrm{pH}$-sensitive polymers including hydroxypropyl methylcellulose phthalate (HPMCP), hydroxypropylmethyl cellulose acetated succinate, and cellulose acetate phthalate (CAP) are widely used for the enteric coating of oral dosage forms to minimize the exposure of probiotics to gastric acids, reducing the loss of probiotic activity in the stomach. ${ }^{30}$ Some selected formulation techniques for oral delivery of probiotics are discussed as follows.

\section{Oral Films}

In recent years, orally dissolving or disintegrating films (ODFs) have gained a great attention as a patient-centric formulation. When placed on the tongue, ODFs immediately hydrate in the saliva and then dissolve and liberate rapidly the active substances in the mouth. ${ }^{31}$ ODFs are generally composed of active ingredients, film- forming polymers, and plasticizers, in combination with functional excipients including sweeteners, flavors, and colors based on specific needs. ${ }^{32}$ Taste masking, particularly for bitter or unpleasant tastes is important since ODFs are dissolved in the mouth. ODFs have some therapeutic benefits including ease of administration without water intake, no risk of choking, easy transportation, and rapid onset of action, providing a marketing advantage with increased patient compliance. ${ }^{33}$ Particularly, ODFs are attractive for pediatrics, geriatrics, bedridden patients, and patients having functional dysphagia. In addition, ODFs can bypass the GI tract, preventing the destabilization of active ingredients in the GI tract. ${ }^{33}$ Therefore, ODFs are actively pursued as a promising oral dosage form for delivering viable probiotics to promote oral health. For example, Heinemann et al formulated ODF for delivering probiotics, in which Lactobacillus acidophilus or Bifidobacterium animalis subsp. lactis was entrapped in a matrix composed of starch, gelatin, and carboxymethyl cellulose. Probiotics were viable in this ODF formulation for 90 days of 
storage. ${ }^{34}$ Recently, Lordello et al developed ODF for the local delivery of Enterococcus faecium CRL183 to the oral cavity. ${ }^{35}$ This ODF formulation was composed of carboxymethylcellulose, gelatin, and potato starch. Probiotics in the ODF were viable up to 90 days of storage at room temperature, demonstrating significant anti-fungal activity against Candida albicans. ${ }^{35}$ Doddo et al fabricated xylitol $(0.5 \%)$ based-ODF with Streptococcus salivarius using a novel inkjet printing technique. This ODF showed significant antibacterial activity against Streptococcus mutans. $^{36}$

Mucoadhesive buccal films are different from ODFs, in that mucoadhesive films are retained inside the buccal cavity, so that the contact time of the formulation with the buccal mucosa is increased, resulting in the prolonged release of active ingredients to the whole buccal cavity or specific mucosa lesions. For example, Abruzzo et al fabricated hydroxypropylmethylcellulose (HPMC)-based mucoadhesive buccal film for the local release of L. brevis CD2 having anti-inflammatory effect. ${ }^{37}$ The developed formulation retained good viability and activity of arginine deiminase of $L$. brevis $\mathrm{CD} 2$ during the storage at $2-8{ }^{\circ} \mathrm{C}$ and exhibited good mucoadhesive properties, resulting in the prolonged release of viable probiotics for the treatment of oral pathologies. ${ }^{37}$ Similarly, Ferreira et al developed mucoadhesive wafers for the buccal delivery of Bifidobacterium bifidum BB12 by using a polymer blend of Carbopol $974 \mathrm{P}^{\circledR}$ and poloxamer 407. ${ }^{38}$ The developed mucoadhesive formulation was suitable for the buccal application of probiotics with good mechanical properties, mucoadhesiveness, and cell viability for 14 days-storage. ${ }^{38}$

\section{Powder/Granules}

Most commercially available probiotics are formulated in the form of powders or granules. The possibility to administer a large dose of probiotics, rapid dissolution, low cost, and flexibility in compounding solids are advantages of powders. Among various formulation techniques adopted to prepare the powder formulations with improved viability of probiotics, freeze-drying (FD) is the most common method for drying heat-sensitive ingredients, maintaining a sufficient quantity of viable probiotics; however, it is a time-consuming process. ${ }^{39,40}$ Spray-drying is also a common technology to concentrate probiotics. While spray-drying has a low operation cost and high production rate, probiotics are exposed to heat and dehydration damage during spray-drying. ${ }^{41}$ Therefore, to overcome the limitations associated with freeze-drying and spray- drying, spray freeze-drying was developed by combining spray-drying and freeze-drying processes to achieve a fine powder preparation. ${ }^{40}$ In spray freeze-drying, the droplets formed by spraying the solution are immersed in liquid nitrogen and solidified by freeze-drying. Spray freezedrying requires less time than freeze-drying, and powders obtained by spray freeze-drying have a larger surface area than those prepared by spray-drying. ${ }^{40}$ Her et al developed a fine powder formulation of Lactobacillus casei (IFO 15883) using spray freeze-drying technique. ${ }^{42}$ The formulated probiotics had a $97.7 \%$ of survival rate under the optimized spray freeze-drying conditions. Since dried probiotics may undergo stressful processes during their production, the drying method and process should be selected carefully. In addition, growth media compositions and protective agents can affect the viability of probiotic powders. Therefore, the optimization of the drying process and formulation variables is critical for the development of stable probiotic powders. $^{43}$

Probiotics granules are also common. The process involves wet or dry granulation to yield free-flowing agglomerated particles with desired physical properties including size, hardness, porosity, density, and uniform particle distribution. ${ }^{44}$ Granules are suitable to dispense a large dose of probiotics and are convenient to consume. Granules are easier to handle than powders because they do not produce dust and have better flowability and compressibility properties. Granules can be coated with various polymers to enhance the stability of acid-labile probiotics or to control the release rate of probiotics. For example, Pyar et al prepared enteric-coated granules containing Lactobacillus acidophilus ATCC 4962. ${ }^{45}$ After wet granulation with L. acidophilus, corn starch, lactose monohydrate, and polyvinylpyrrolidone, the probiotic granules were coated with Eudragit L30D-55, an enteric polymer, to avoid the probiotic release in acidic environment. Probiotics within the enteric coated granules were protected from the gastric environment and therefore could exhibit enhanced bioactivity. ${ }^{45}$ Aponte et al also fabricated granules for the co-delivery of L. plantarum 299v and standardized extract of Olea europaea leaves (Phenolea ${ }^{\circledR}$ Active F) via wet granulation with corn starch, lactose monohydrate, and microcrystalline cellulose. ${ }^{46}$ The granules maintained the viability of $L$. plantarum $299 \mathrm{v}$ for more than 6 months upon storage at $4^{\circ} \mathrm{C}$. In addition, analysis of the Lactobacillus population in feces from mice treated with these granules confirmed that the probiotics were alive when they reached the colon. 


\section{Tablet and Capsule}

Tablets and capsules are convenient solid dosage forms to deliver probiotics. These formulations allow the application of various functional excipients to improve the shelflife, GI stability, cell viability, and also to control the release rates and target sites of probiotics. Recently, Kim et al developed tablets of L. reuteri LRT18 using a pHsensitive phthalyl inulin to protect probiotics from acidic conditions in the stomach. ${ }^{30}$ The phthalyl inulin-coated tablets improved the cell survival in the harsh gastric conditions and rapidly released the probiotics in the intestinal fluids. These tablets could maintain probiotic viability over 6-months of storage under refrigeration. ${ }^{30} \mathrm{Kim}$ et al also developed a novel bi-coated combination capsule of probiotics and mosapride for the treatment of irritable bowel syndrome. ${ }^{47}$ Hard gelatin capsules containing acid labile probiotics were coated with an enteric polymer HPMCP (hypromellose phthalate or hydroxypropylmethylcellulose phthalate), and then additionally coated with various hydrophilic polymer solutions containing mosapride. ${ }^{47}$ Among the various polymers used, the enteric-capsule coated with mosapride/HPMC had significantly improved the solubility and the oral bioavailability of mosapride, while acid-labile probiotics were protected from the harsh gastric conditions. ${ }^{47}$ Consequently, enteric gelatin capsules coated with drug/polymer can be a promising approach for effective combination therapy with acid-labile probiotics and poorly water-soluble drugs with enhanced GI stability and oral bioavailability.

Dodoo et al prepared capsules for the site-specific colonic delivery of probiotics using Phloral ${ }^{\circledR}$ technology. ${ }^{48}$ Phloral $^{\circledR}$ technology is a colonic coating technology integrating pH-dependent and bacterially-triggered systems, consisting of an enzyme-sensitive component (natural polysaccharide) and a $\mathrm{pH}$-sensitive polymer (Eudragit ${ }^{\circledR} \mathrm{S}$ ) to facilitate fail-safe drug release in the colon. ${ }^{49}$ They loaded probiotics (three commercial probiotics [lactobacilli strains] and in-house freeze-dried Lactobacillus acidophilus LA5) into capsules and then coated the capsules using Phloral ${ }^{\circledR}$ coating technology. Encapsulation of probiotics into the capsules coated by Phloral ${ }^{\circledR}$ technology exhibited approximately $90 \%$ viabilities when exposed to gastric acids for 2 $\mathrm{h}$ and achieved over $60 \%$ adhesion to intestinal cells. ${ }^{48}$ Recently, Falco et al also demonstrated that sulfated $\beta$ glucan and chitosan are suitable coating materials for the targeted delivery of probiotics to the intestine. ${ }^{50}$ The sulfated $\beta$-glucan as the exterior layer prevented attachment to the gastric mucosa, and chitosan prevented disintegration of the coating in the acidic gastric conditions. The layer-bylayer coating of probiotics with oppositely charged chitosan and sulfated $\beta$-glucan may ensure a safe passage of probiotics through the stomach and release probiotics in the intestine. $^{50}$

An orodispersible tablet (ODT) formulation can be also applied for delivering probiotics. An ODT disintegrates rapidly in the mouth within a minute and is taken without water; thus, it is a convenient dosage form with fast onset of action. However, adequate residence time of probiotics in the oral cavity is required to maximize their therapeutic benefit in oral diseases (eg, dental caries, gingivitis, or periodontitis). Therefore, to extend the contact time between probiotics and oral mucosa without delaying disintegration, Hoffmann et al developed a mucoadhesive ODT of L. plantarum Lp299v. ${ }^{51}$ They fabricated the ODT by incorporating mucoadhesive polymers (Carbopol 971P NF, Metolose 65SH50, or chitosan) into the tablet either by direct compression or after granulation with the probiotics. The directly compressed ODTs having Carbopol 971P NF exhibited superior long-term stability over 30 months of storage under refrigerated conditions and retained high mucoadhesion properties after the longterm storage. ${ }^{51}$

\section{Hydrogel}

Hydrogels are three-dimensional cross-linked networks of water-soluble polymers. A hydrogel can be formulated as micro-/nano-particles or as films using biopolymers and/or polyelectrolytes. ${ }^{52}$ Hydrogels are commonly used in clinical practice owing to their tunable physical properties, biocompatibility, capability to protect drugs from degradation, and controllable drug release. ${ }^{52}$ In addition, the mucoadhesive properties of some hydrogels are advantageous in immobilizing them at the site of administration. For the entrapment of probiotic microorganisms into the hydrogel matrix, the ionotropic gelation technique seems to be suitable, which involves cross-linking via the interaction between oppositely charged ions. ${ }^{53}$ As a physical cross-linking method, the ionotropic gelation does not require potentially toxic cross-linking agents and avoids elevated temperatures, minimizing thermal stress that could otherwise damage the probiotic cell wall. ${ }^{54}$

In recent years, polysaccharide-based hydrogel systems have become popular because of their ability to provide a physical barrier between encapsulated probiotics and the harmful environment. These systems not only enhance the viability of probiotic bacteria in the 
GI tract but also improve their stability under various storage conditions. ${ }^{55}$ Since polysaccharides are biocompatible, biodegradable, and not too expensive, numerous polysaccharides including chitosan, pectin, alginate, carrageenan, and xanthan are used for delivering probiotics either alone or as a combination of two polysaccharides or a polysaccharide and a non-polysaccharide. ${ }^{55}$ These polysaccharide-based hydrogel systems should have an adequately small pore size compared to the dimensions of bacteria cells, thus retaining the entrapped probiotics in the hydrogel matrix until degradation of the network. Dafe et al incorporated L. plantarum cells into pectin/ starch hydrogels by the extrusion method. ${ }^{56}$ The viability of encapsulated probiotic cells in simulated gastric fluid or bile salt solution was significantly higher than that of nonencapsulated cells, implying that the pectin/starch hydrogel delivery system could protect the probiotics against adverse conditions of the GI tract. ${ }^{56}$ Alginatebased hydrogels are also widely used to encapsulate probiotics. However, such formulations have some disadvantages including uncontrollable swelling, fragility, and leakage of the entrapped probiotics. ${ }^{53}$ To overcome this issue, alginate matrices are often coated with a cationic polysaccharide such as chitosan, minimizing the leakage of the entrapped probiotics. ${ }^{54}$ Cook et al encapsulated Bifidobacterium breve into alginate matrices and then subjected to layer-by-layer coating of alternating alginate and chitosan. ${ }^{57}$ These multilayercoated beads showed better protection of probiotics in the acidic condition than uncoated beads. The viability of probiotics was enhanced from $<3 \log (\mathrm{CFU} / \mathrm{mL})$ to $8.84 \pm 0.17 \log (\mathrm{CFU} / \mathrm{mL})$ in a three-layer coated matrix. $^{57}$

Synthetic polymers including polyvinyl alcohol (PVA), poly methyl methacrylate, poly (D,L-lactic-co-glycolic acid), polyethylene glycol, polyethylene oxide, and polyacrylamide have been also used for the development of hydrogels. ${ }^{58}$ These synthetic polymers have low immunogenicity and their mechanical properties and physicochemical properties can be easily controlled. ${ }^{59,60}$ However, the application of synthetic polymers to probiotics is still limited because organic solvents used in the preparation can cause cell damage.

\section{Nasal Delivery}

Nasal delivery of probiotics may be a promising approach for the management of airway diseases since it allows modulation of the epithelial barrier function and the immune system. ${ }^{61}$ Imbalance of the microbiota composition, also known as dysbiosis, causes the development or exacerbation of chronic inflammatory diseases including chronic rhinosinusitis and asthma. ${ }^{62}$ It was recently found that probiotics can ameliorate dysbiosis by interacting with pattern recognition receptors recognizing microbe- or pathogen-associated molecular patterns (MAMPs or PAMPs) expressed by microbes. ${ }^{63}$ Furthermore, this interaction can modulate tight junctions and adherence junctions, restoring the defective epithelial barrier. ${ }^{62}$ Probiotics can also modulate host immune responses via interactions with dendritic cells. ${ }^{62,64}$ Therefore, nasal delivery of probiotics can help in the treatment of various airway diseases.

Nasal delivery systems are non-invasive, easy to selfadminister, and allow a fast onset of action. ${ }^{65}$ Moreover, they can avoid the harsh acidic environment of the GI tract. $^{66}$ Generally, the nasal route of administration is applicable for both local and systemic delivery of drugs as solutions, gels, spray, suspensions, emulsions, liposomes, and micro-/nano-particles. Various physicochemical properties of formulations (particle size, osmolality, viscosity, mucoadhesiveness, etc) can affect the residence time and host-microbiota interaction. ${ }^{65,67}$ In addition, the physiological and anatomical factors including membrane permeability, $\mathrm{pH}$, nasal blood flow, nasal enzymes, mucin secretion from goblet glands, and mucociliary clearance can affect the efficiency of the nasal delivery of probiotics. ${ }^{65,67}$ Disease states like nasal atrophic rhinitis and severe vasomotor rhinitis could also impact the extent of nasal drug delivery. ${ }^{67}$ Therefore, various pharmaceutical and physiological factors should be addressed in the formulation design for the nasal delivery of probiotics.

Among the nasal formulations, nasal spray is commonly used in clinical practice. Marchisio et al reported that a nasal spray of Streptococcus salivarius 24SMB reduces the risk of acute otitis media in otitis-prone children. $^{68}$ Likewise, Mantia et al and Cantarutti et al also revealed that a nasal spray of Streptococcus salivarius 24SMB and Streptococcus oralis 89a effectively prevent the recurrence of acute otitis media in children. ${ }^{69,70}$ Moreover, Jokicevic et al prepared a nasal formulation of the novel probiotic strain, L. casei AMBR2 derived from the upper respiratory tract (URT) by spray drying that could retain the viability and morphology of probiotic bacteria. $^{71}$ This formulation was suitable in terms of the high degree of adherence on Calu-3 cells and antimicrobial 
activity against upper respiratory tract pathogens during antimicrobial assays with the respiratory cell line. ${ }^{71}$

\section{Topical Skin Delivery}

The delivery of probiotics through the skin is an attractive approach since it is noninvasive and has many advantages including avoidance of GI degradation, controlled drug release, ease of self-medication, and high patient compliance. ${ }^{72}$ Given that skin microbes in the epidermis and dermis play an important role in maintaining skin health and preventing pathogen invasion, the effective dermal delivery of probiotics may regulate local skin immunity. ${ }^{73}$ Particularly, viable probiotics delivered through the skin can produce large amounts of lactic acid and reduce the $\mathrm{pH}$ of the skin, thereby inhibiting the growth of pathogenic bacteria and improving skin immunity. ${ }^{74,75}$ Before reaching the target sites within the skin, probiotics applied on the skin must first penetrate the stratum corneum, which is a major barrier against the perfusion of large hydrophilic molecules since molecules with $\log \mathrm{P}$ value of 1-3 and a molecular mass less than $500 \mathrm{Da}$ can only efficiently penetrate the intact stratum corneum. ${ }^{76}$ Consequently, the low permeability of probiotics across the stratum corneum makes it very difficult to deliver such probiotics through the skin.

Various approaches have been attempted to enhance the skin permeation of macromolecules including the use of absorption enhancers, iontophoresis, electroporation, sonophoresis, and microneedles. ${ }^{77}$ Among them, microneedles hold promising potential for the effective dermal delivery of probiotics. Microneedles are noninvasive or minimally invasive devices having tiny needles of 50-900 $\mu \mathrm{m}$ length. ${ }^{78}$ They can penetrate the stratum corneum and release probiotics in the epidermis or dermis depending on the needle length, thereby enhancing the skin permeation and the local delivery of probiotics. ${ }^{79}$ The first generation of microneedle arrays was fabricated with silicon, metals, or organic polymers to create micro-pores into the skin for drug diffusion. ${ }^{80}$ In recent years, microneedles are prepared out of materials that dissolve rapidly in the skin to release drugs, making this a safe and pain-free route of administration. ${ }^{81}$ Dissolvable microneedles have been demonstrated to be effective in delivering macromolecules including vaccines and protein drugs. ${ }^{78}$ However, the local skin delivery of probiotics using dissolving microneedles is rarely reported. Recently, Chen et al demonstrated that dissolvable microneedles could effectively deliver viable Lactobacillus into the skin without stimulating the nerves and causing pain. ${ }^{82}$ As illustrated in Figure 1, sodium carboxymethyl cellulose based-microneedles containing Lactobacillus were prepared using a centrifugation casting method without compromising the viability and integrity of Lactobacillus. ${ }^{82}$ These microneedles rapidly dissolved after skin penetration, releasing Lactobacillus into the dermis without local skin irritation. Furthermore, the released Lactobacillus actively synthesized lactic acid in rats, indicating that dissolving microneedles could deliver the biologically active Lactobacillus. ${ }^{82}$ Therefore, dissolving microneedles should be an effective new avenue for the topical delivery of probiotics to improve skin health and immunity.

\section{Vaginal Delivery}

Probiotics can be administered into the vagina to restore the normal vaginal microbiota and prevent infections. ${ }^{83,84}$ Normal and healthy vaginal microflora mainly comprise lactobacilli and provide a bacterial barrier against uropathogens in the vagina. ${ }^{85}$ However, the imbalance of vaginal microflora caused by various factors including hormonal changes in the postmenopausal phase, pregnancy, and treatment with antibiotics or antifungal drugs, increases the susceptibility of vaginal infections (bacterial vaginosis, complicated vulvovaginal candidiasis, etc) ${ }^{85}$ Therefore, the supplementation of exogenous lactobacilli may be helpful to optimize the vaginal microbiota and maintain vaginal health. Orally administered lactobacilli have been demonstrated to reduce pathogenic bacteria in the vaginal microbiota. ${ }^{86}$ However, the functional activity of lactobacilli after oral administration is fully dependent on their stability and survival in the GI tract. Therefore, vaginal administration should be an attractive alternative for the effective local delivery of probiotics to maintain vaginal health because it can bypass the GI tract and has some advantages including noninvasiveness, selfmedication, relatively low enzymatic activity in the vagina, local effect with reduced systemic toxicity, and capability for prolonged drug action. ${ }^{87}$ Various vaginal formulations are available including powders, suppositories, tablets, capsules, gels, and foams. ${ }^{88}$ In addition, mucoadhesive polymers such as alginate, pectin, and chitosan can be incorporated into the formulation to extend the residence time in the vagina. ${ }^{89}$ Some of the formulation approaches for the vaginal delivery of probiotics are discussed below.

\section{In-situ Gels}

It is critical for vaginal formulations of probiotics to maintain a prolonged residence time in the vagina to achieve 


\section{A Fabrication process}

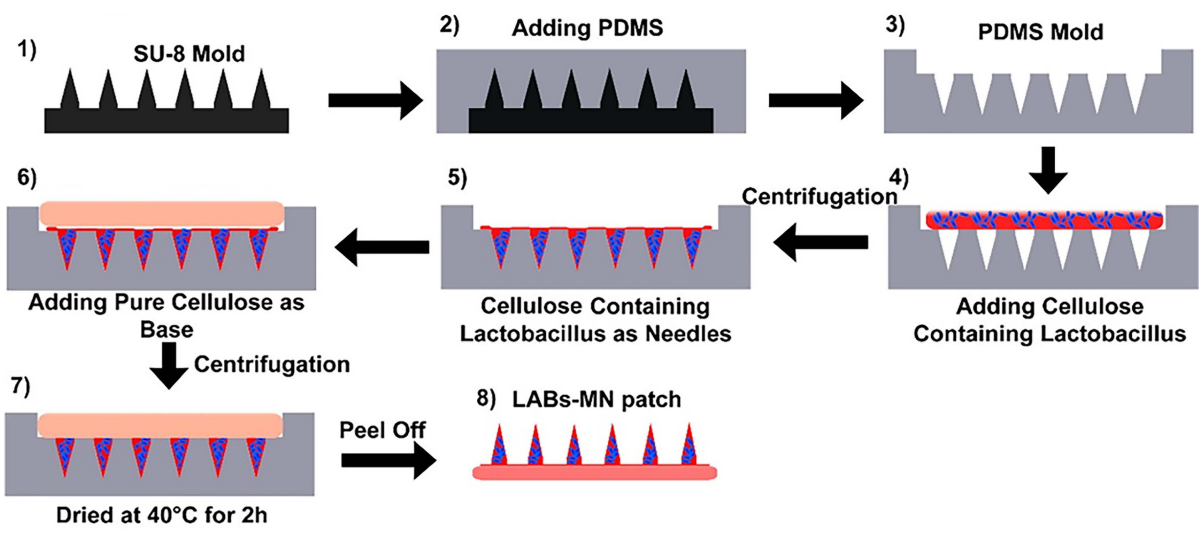

\section{B Photographic and SEM images}
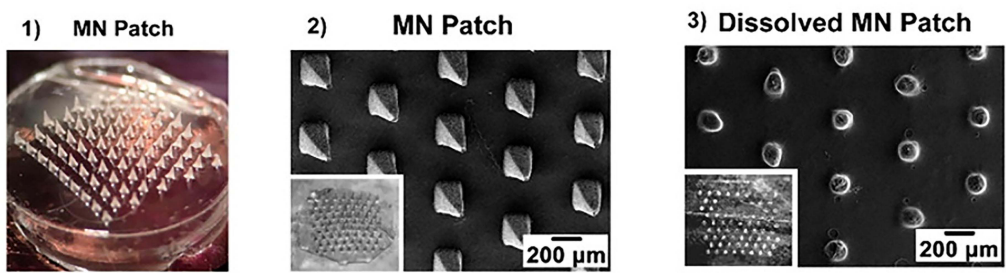

Figure I Fabrication of the dissolvable microneedle patches loaded with Lactobacillus: (A) Fabrication process and (B) Photographic and SEM images; Adapted with permission from Chen HJ, Lin DA, Liu F, et al. Transdermal delivery of living and biofunctional probiotics through dissolvable microneedle patches. ACS Applied Biomater. 2018; I (2):374-38I. Copyright (C) 2018, American Chemical Society. ${ }^{82}$

therapeutic effects. In situ gelling systems have been proposed as an alternative for the local administration of various therapeutics. These systems are fluids before administration but undergo in situ sol-gel transition upon contact with biological fluids in response to various stimuli including change in $\mathrm{pH}$, temperature, and concentration of ions. ${ }^{90}$ Thermogelling systems have been used to extend the residence time of vaginal formulations; these systems have low viscosity at room temperature for easy administration into the vaginal cavity but undergo in situ gelation at body temperature. ${ }^{91}$ Among various polymers, poloxamers are widely used for the development of thermogelling systems due to their thermo-reversible behavior in aqueous solutions. ${ }^{92}$ Furthermore, hydrophilic mucoadhesive polymers are often added into thermogelling systems to improve their interaction with the mucosa and prolong the retention time in the vaginal cavity. Vigani et al developed a mucoadhesive in situ gelling formulation for the vaginal delivery of Lactobacillus gasseri to avoid the recurrence of candidosis. ${ }^{90}$ This vaginal formulation was prepared by combining thermosensitive polymers (a blended mixture of poloxamer 407 and methyl cellulose), a bioadhesive and moisturizing agent (xyloglucan), and an acidifying agent (pectin).$^{90}$ The developed formulation underwent gelation at $37{ }^{\circ} \mathrm{C}$ upon dilution in simulated vaginal fluid and preserved the viability of the administered probiotic microorganism while restoring the physiological vaginal environment. ${ }^{90}$

\section{Tablets}

Vaginal tablets show some advantages including the capability for precise dosing, easier handling and storage, low manufacturing cost, and ease of administration. In comparison to oral tablets, vaginal tablets can improve the stability of probiotics since they are directly applied to the target site and bypass the harsh environment of the GI tract. ${ }^{93}$ Similar to oral tablets, vaginal tablets can be designed with additional characteristics such as bioadhesion, sustained release of active ingredients, and rapid disintegration by using various functional excipients and formulation techniques. ${ }^{94}$ Sanchez et al developed a bilayered mucoadhesive vaginal tablet of Lactobacillus subsp. bacteria for the treatment of vulvovaginal infections. ${ }^{88}$ This vaginal tablet consisted of two layers (fast- and slow-release layers) containing the same number of lactobacilli bacteria. This bi-layered tablet consisted of 
a fast-release layer containing an effervescent mixture to accelerate layer disintegration and a slow-release layer containing carbopol ${ }^{\circledR} 934$ and chitosan for achieving the prolonged release of probiotic bacteria. This formulation maintained the cell viability and exhibited dual release profiles (immediate release from the effervescent layer and prolonged release from the matrix layer). ${ }^{88}$ Recently, Vicariotto et al also evaluated the effectiveness of slowrelease vaginal tablet containing probiotics in women with bacterial vaginosis. ${ }^{95}$ They fabricated vaginal tablets using tara gum, arabinogalactan, fructooligosaccharide, and probiotics (L. fermentum LF15 and L. plantarum LP01). The results from clinical studies indicated that the vaginal delivery of probiotics could effectively inhibit acute Gardnerella infections and significantly improve the related uncomfortable symptoms. ${ }^{95}$ Maggi et al developed vaginal tablets containing different strains of lactobacilli (L. brevis, L. salivarius, and L. plantarum) ${ }^{96}$ Each of three strains was prepared as a fast-release or slow-release vaginal tablet (single layer). Fast-release vaginal tablets showed higher viability of probiotics than slow-release vaginal tablets during 1 year of storage. ${ }^{96}$ This result suggests that a fast-release vaginal tablet containing Lactobacilli may be more feasible for industrial production. ${ }^{96}$ Mastromarino et al also demonstrated the effectiveness of lactobacilli vaginal tablets in the treatment of symptomatic bacterial vaginosis in women. ${ }^{97}$ After the administration of a fast-release vaginal tablet once a day at bedtime for 7 days, vaginal anaerobic microorganisms and vaginal concentration of polyamines in patients were significantly decreased, implying the therapeutic benefit of vaginal delivery of probiotics. ${ }^{97}$

\section{Suppository}

Vaginal suppositories are common mainly because they are easy to self-administer without an applicator. ${ }^{93}$ These suppositories can be prepared using various excipients including cocoa butter, oils and fats, glycerinated gelatin, and polyethylene glycols. Based on the combination of these excipients, suppositories are categorized into two major types: lipophilic or hydrophilic suppositories. ${ }^{98,99}$ The lipophilic fat-based suppositories melt at body temperature to release the active ingredients, whereas hydrophilic suppositories require dissolution in the vaginal fluids to release the active ingredients. Suppositories dissolve faster than vaginal tablets, leading to a rapid onset of action. ${ }^{100}$ Rodrigues et al developed both solid body and hollow-type suppositories for the vaginal delivery of
Lactobacillus acidophilus. ${ }^{101}$ They used polyethylene glycol 400 and 4000 or Witepsol H12 as a hydrophilic and hydrophobic base, respectively, where L. acidophilus was incorporated in the molten mass before molding solid body suppositories or added as suspension into the cavity of hollow-type suppositories. ${ }^{101}$ The results suggest that hollow-type suppositories are promising for vaginal delivery when sustained release and high viability of probiotics are required. ${ }^{101}$ Camilletti et al also developed vaginal ovules containing L. fermentum L23 and L. rhamnosus L60, demonstrating that these vaginal formulations maintained not only lactobacilli viability during storage at $4{ }^{\circ} \mathrm{C}$ for 180 days but also retained their antimicrobial and biofilmproducing ability. ${ }^{102}$ Kale et al developed vaginal suppositories containing Bacillus coagulans. ${ }^{103}$ They prepared three suppositories with cocoa butter-base, glycerinated gelatin-base, and PEG 1000-base, respectively by the molding method. Probiotics released from glycerinated gelatin suppositories were viable and produced lactic acid and hydrogen peroxide, exhibiting antipathogenic activity. ${ }^{103}$

Verdenelli et al also developed vaginal ovules containing a mixture of L. rhamnosus IMC501 ${ }^{\circledR}$ and L. paracasei IMC $502^{\circledR} .^{104}$ They prepared and evaluated two different ovules: polyethylene glycol (PEG) 1500-based ovule and Witepsol ${ }^{\circledR} \mathrm{H} 15$-based ovule. The ovules were prepared by melting each base at $50^{\circ} \mathrm{C}$ and cooling down until it starts to solidify. Then, lyophilized bacterial strains (L. rhamnosus IMC $5011^{\circledR}$ and L. paracasei IMC $502^{\circledR}$ ) were added into each base and mixed well. ${ }^{104}$ The obtained mixture was poured into plastic stencils and cooled down at room temperature. After 6 months of storage at $4{ }^{\circ} \mathrm{C}$, Witepsol ${ }^{\circledR} \mathrm{H} 15$-based ovule showed the higher viability of Lactobacilli than that of PEG 1500based ovule. ${ }^{104}$

\section{Rectal Delivery}

Inflammatory bowel disease (IBD) may be caused by inappropriate an immune response to intestinal bacteria and an imbalance in the enteric microbiota in genetically susceptible individuals. ${ }^{105,106}$ Therefore, intestinal microbiota plays an important role in the treatment of IBD and the intake of probiotic bacteria should be beneficial for induction and maintenance of remission in IBD. ${ }^{105,106}$ Particularly for ulcerative colitis, rectal administration can be a promising route of administration for the targeted delivery of probiotics to the inflamed colon. It can bypass the GI tract, avoiding the destabilization of 
Table 2 Examples of Microencapsulation Approaches for Probiotic Formulations

\begin{tabular}{|l|l|l|c|}
\hline Probiotics* & Methods & Encapsulating Materials & Reference \\
\hline Lactiplantibacillus plantarum & Spray drying & Skim milk, whey protein isolates, trehalose, & {$[$ lI16] } \\
Limosilactobacillus reuteri & Fluidized bed drying & Shellac/sodium alginate, chitosan/arabic gum & {$[130]$} \\
Lactobacillus acidophilus & Extrusion & Alginate, chitosan & {$[134]$} \\
Lacticaseibacillus rhamnosus & Emulsification & Concentrated sweet whey & {$[143]$} \\
Ligilactobacillus salivarius & Emulsification & Anhydrous milk fat, whey protein isolate, pectin & {$[144]$} \\
Bifidobacterium animalis subsp. lactis/Lactobacillus acidophilus & Coacervation & Casein/pectin & {$[149]$} \\
Limosilactobacillus reuteri & Coacervation & Gelatin/sodium caseinate & {$[150]$} \\
\hline
\end{tabular}

Note: *Probiotics names presented in the cited references are updated with the recent taxonomic classification.

probiotics before reaching the colon. Furthermore, since a common mechanism of probiotics is the adherence of probiotic bacteria to the mucosal surface of the intestine and preventing the colonization of pathogenic microorganism, ${ }^{107,108}$ rectal administration might be a good option for the targeted delivery of probiotics to the colon, because it increases the adherence of probiotic bacteria to the inflamed area and attenuates the inflammation. D'Incà et al evaluated the effect of probiotics after oral and rectal administration of $L$. casei DG in patients with mild ulcerative colitis, ${ }^{109}$ and found that patients treated with rectal $L$. casei, in combination with oral 5-aminosalicylic acid had significantly restored colonic microbiota with decreasing Enterobacteriaceae and improved mucosal cytokine balance while oral administration of $L$. casei in combination with 5-aminosalicylic acid did not lead to a significant improvement. ${ }^{109}$ Romach et al also compared the effect of oral and rectal administration of anti-inflammatory probiotics, YOMIX $^{\text {TM }}$ Y 109 FRO 1000 and Lactobacillus GG, on the morphology, gene expression, and colonic microbiota in colitis-induced rats. ${ }^{110}$ They found that the rectal administration of probiotics was superior to the oral administration in attenuating the inflammation and suggest that the targeted delivery of probiotic bacteria into the colon via rectal administration should be beneficial in the treatment of IBD. ${ }^{110}$ Oliva et al also evaluated the effect of L. reuteri ATCC 55730 enema on inflammation and cytokine expression in children having active distal ulcerative colitis. ${ }^{111}$ The patients received an enema solution containing L. reuteri ATCC 55730 in combination with oral mesalazine for 8 weeks. This combination therapy significantly reduced mucosal inflammation and the expression level of pro-inflammatory cytokines (IL-1 $\beta$, TNF- $\alpha$ and IL-8). ${ }^{111}$

\section{Microencapsulation Technology for Probiotics}

Most strains of probiotics are vulnerable to various environmental stressors, resulting in their low viability and loss of activity during their manufacturing and storage. Particularly, the stability of probiotics is significantly affected by processing stress such as heating and cooling, oxygen, and shear stress. ${ }^{112}$ Therefore, the stabilization of probiotics is critical in the formulation development of probiotics regardless of the route of administration. In the microencapsulation of probiotics, the probiotics are entrapped within tiny particles or core shells surrounded by coating materials. ${ }^{113}$ Microencapsulation provides the probiotic microorganisms a physical barrier against the detrimental environment, enhancing their viability during production, storage or clinical application. Furthermore, microencapsulation can be used to control the release rate and sites of probiotics, thereby optimizing the therapeutic benefits of probiotics. ${ }^{113}$ In general, the quality and the success of microencapsulation mainly depend on the strains of probiotics, the coating materials, and the method of microencapsulation. ${ }^{113}$ Natural or synthetic polymers are used alone or in combination to form the desired coating layer. ${ }^{29}$ Particularly, to extend the residence time at the target site, mucoadhesive polymers are often utilized in the microencapsulation of probiotics. In many cases, microencapsulation techniques are commonly used for the stabilization of probiotics, and then additional formulation techniques are applied to the microencapsulated probiotics to fabricate the final dosage form according to the route of administration. Therefore, this review also covers various microencapsulation techniques applied for formulating probiotics, including spray drying, freeze drying, fluid bed drying, extrusion, and emulsification (Table 2). More details on these methods are described below. 


\section{Spray-Drying}

Spray drying is a commonly used technique for prolonging the storage of probiotics. It is an economic process with relatively low operating costs and has many advantages including production of flowable powders, fast drying rate, scalability, and control over particle size. ${ }^{114}$ To use the spray drying technique for microencapsulation, probiotics are dissolved in the encapsulating agent having emulsifying or film-forming properties. Various natural polymers including proteins and carbohydrates or their derivatives are used as encapsulating agents for probiotics. ${ }^{115-117}$ Spray-drying process involves the atomization of sprayed liquid droplets in a hot air drying chamber, and dry powders are obtained when water from the atomized droplets was evaporated under controlled temperature and airflow conditions. ${ }^{113}$ The thermal and oxidative stress during spray drying can damage the cell wall or cellular components like cytoplasmic membrane and proteins, thereby reducing the viability of probiotics. Therefore, the drying process parameters including inlet and outlet temperature control, air flow rate, and humidity should be optimized to minimize cell death. ${ }^{118}$ Protective agents are also added to minimize the bacterial inactivation during drying. Commonly used protectants include carbohydrates, proteins, lipids, and gums, as exemplified with trehalose, granular starch, non-fat milk solids, and growth promoting factors. ${ }^{113,119}$ Particularly, skim milk, whey protein isolates (WPI), and non-reducing disaccharides (eg, trehalose, lactose and sucrose) are the most commonly used protective agents for probiotics during spray drying. ${ }^{115}$ Khem et al demonstrated that skim milk, whey protein isolates, trehalose, and lactose could protect L. plantarum A17 during drying. These protective agents were assumed to protect cytoplasmic membrane of probiotic cells from dehydration. ${ }^{116}$ Low molecular weight carbohydrates such as sugars stabilize the membrane and protein chains of cellular macromolecules in a dry state through hydrogen bonding. ${ }^{120}$ Moreover, the combined use of protein and sugar as protectants have a synergistic effect in enhancing cell viability. ${ }^{120}$ Various strains of lactobacillus and bifidobacterium have been successfully dried using spray drying approach. For example, Farahmandi et al evaluated the viability of L. rhamnosus during the spray drying process and found that the micro-encapsulated cells were 5-fold more stable than un-encapsulated probiotic cells during 20 days of storage, confirming the positive effects of micro- encapsulation on the shelf-life of probiotics. ${ }^{121}$ In addition, they demonstrated that sub-lethal stress treatments (heat, hydrogen peroxide, and sodium chloride) of probiotic bacteria before microencapsulation via spray-drying effectively increase L. rhamnosus resistance to harsh conditions. $^{121}$

In general, spray drying technology offers high manufacturing capacity at relatively lower cost to produce a stable powder form. However, the impact of stress (high temperature, dehydration) should be carefully considered.

\section{Freeze- and Vacuum-Drying}

Freeze-drying is also known as lyophilization and is widely used to solidify thermally sensitive probiotics. The freeze drying process includes three steps such as freezing, primary drying, and secondary drying. Although it is more expensive and takes more time than spray drying, it is useful to encapsulate thermally sensitive probiotics. ${ }^{122}$ First, probiotics are frozen in the presence of carrier materials at low temperatures and then under vacuum, the frozen water is sublimated directly from the solid phase to the gas phase. ${ }^{122}$ Although this method can minimize thermal stress, the formation of ice crystals in the freezing step may induce mechanical stress, leading to cell death. ${ }^{122}$ Given that the growth of ice crystals is affected by the freezing rate and temperature, a high freezing rate is preferable as it forms smaller ice crystals preventing extensive cell damage. ${ }^{123}$

The crystallization of water can also lead to chemical and osmotic damage. Therefore, to enhance the viability of probiotics against the detrimental environments during freeze drying and subsequent storage, cryoprotectants such as sugars and polyols are frequently mixed with the carrier materials since they help preserve the integrity of the cell membrane. ${ }^{120}$ Sugars and sugar derivatives are effective in protecting probiotics as the hydroxyl groups of carbohydrates replace water. Polyols prevent oxidative damage by scavenging free radicals and also act as effective cryoprotectants in the freeze drying of probiotics. ${ }^{124-126}$ Considering that the type and properties of cryoprotectants significantly affect the viability of bacterial cells during freeze drying and subsequent storage, the selection of cryoprotectants is important for process optimization. The freeze-dried probiotics may be additionally coated to enhance their GI stability and/or control the release of probiotics at the desired target.

As an alternative to freeze-drying, low temperature vacuum drying has been also applied to encapsulate probiotics. While similar to freeze-drying, the drying occurs 
by evaporation instead of sublimation. Vacuum drying temperatures are lower than spray drying temperatures but higher than freeze-drying temperatures. ${ }^{127}$ Although dehydration stress can occur, vacuum drying is a gentle process with reduced temperature stress (freezing/heating) and oxidative stress, and it may be used for heat-sensitive or oxygen-sensitive probiotics. ${ }^{127}$

\section{Fluidized Bed Drying}

Fluid bed drying is a process wherein cell suspension is sprayed and dried on inert carriers using a fluidized bed coater. ${ }^{128}$ It is less time-consuming than freeze drying but takes longer than spray drying. In addition, fluidized bed drying uses lower drying air temperatures than spray drying, leading to less thermal inactivation. ${ }^{128}$ Generally, the carrier materials are first placed in the fluid bed dryer and then the bacterial suspension is sprayed on the fluidized carriers such as casein, maltodextrin, cellulose, lactose or $\mathrm{NaCl}$ particles. ${ }^{129}$ The main advantage of this process is the use of larger particles, thereby improving the flow characteristics of the obtained powder. ${ }^{127}$ Alternatively, bacterial pellets are prepared first by other drying methods such as freeze drying or spray drying and then the dried particles are encapsulated with various coating materials using a fluid bed dryer to enhance the stability of probiotics. ${ }^{127}$ In both methods, the use of fluidizing air provides a uniform circulation of particles and proper circulation of the particles is key factor to ensure a uniform coating of all particles. Lipids, proteins or carbohydrates are commonly used as coating materials for probiotics subjected to fluidized bed drying. ${ }^{29}$ Double- or multi-coated microencapsulation can be done using fluidized bed drying technique to increase the resistance of probiotics against the detrimental environment or to confer the desired properties to the particles. Zaghari et al prepared double coated $L$. reuteri by fluidized bed drying, in which the microcapsules were coated with shellac and sodium alginate first and then with chitosan and arabic gum. ${ }^{130}$ The double-coated microcapsules had improved resistance against acidic conditions and heat. ${ }^{130}$ Since fluidized bed drying can yield large batch volumes and high throughputs, it is suitable for large-scale production of microencapsulated probiotics. ${ }^{131}$

\section{Extrusion}

Extrusion method is commonly used for obtaining microparticles of probiotics, due to its simplicity, low cost, and gentle formulation conditions ensuring high cell viability. ${ }^{132,133}$ The extrusion based-encapsulation process involves two steps. First, hydrocolloid solutions containing probiotics are extruded through a nozzle, generating small droplets freely dripping into the gelling solution. Then, these small droplets are solidified by gelation or formation of a membrane on their surface, resulting in the production of porous hydrogel beads. ${ }^{132,133}$ An additional polymeric coating is often applied to the obtained hydrogel beads to ensure better survival of the encapsulated probiotic bacteria during storage and in vivo application. The size and shape of droplets depend on multiple process variables including the diameter of the nozzle, the distance between the nozzle and the gelling solution, and the device used. ${ }^{133}$

The commonly used gelling agents in this method are alginate, k-carrageenan, and whey proteins. ${ }^{132,133}$ Particularly, alginate is the most popular for extrusion and is used alone or in combination with other polymers to enhance the viability of probiotic bacteria. ${ }^{134}$ Shah and Ravula encapsulated Bifidobacterium and Lactobacillus acidophilus in calcium alginate, which improved the survival of bacteria cells. ${ }^{135}$ Similarly, Lee et al encapsulated Lactobacillus acidophilus KBL409 with alginate alone and alginate-chitosan mixture using the extrusion method. ${ }^{134}$ Probiotics bacteria in both microspheres had higher survival in the GI tract and better mucoadhesive abilities than free probiotic cells. ${ }^{134}$ Overall, extrusion method is economical, simple, and mild without the use of deleterious solvents and heating; however, slow solidification rates and inefficiency in large-scale production are challenges to overcome. ${ }^{29}$

\section{Emulsification}

An emulsion is a well-dispersed mixture of two immiscible liquids in the presence of emulsifying or surface-acting agents. To entrap the probiotic cells in emulsion, a small volume of an aqueous solution containing probiotic cells is added into a large volume of various vegetable oils including sesame oil and corn oil. ${ }^{136}$ Then, the resulting mixture is homogenized in the presence of emulsifiers, producing water-in-oil (w/o) emulsion. This emulsification method has been proven to be effective in improving the stability of probiotics against the detrimental environment. Hou et al encapsulated lactic acid bacteria (Lactobacillus delbrueckii subsp. bulgaricus) in sesame oil based-emulsion, improving the viability of probiotics in simulated gastric and intestinal fluids by approximately 10,000 folds. ${ }^{137}$

The obtained emulsion may undergo internal or external gelation to ensure the high viability of probiotics. ${ }^{136,138}$ In this process, the aqueous suspension is prepared using 
probiotic cells and polymers as entrapment matrix materials. Once the emulsion is formed, the polymers in the aqueous phase are insolubilized to form tiny gelled beads within the oil phase, and the resultant beads are taken out by filtration. ${ }^{136}$ The selection of the gelation method depends on the properties of polymers used as matrix materials, and the size of beads is controlled by the speed of agitation. ${ }^{136}$ For example, in emulsification/external gelation method, alginate solution is dispersed in the oil phase to form w/o emulsion, and then calcium chloride solution is added for gelation. In the case of the emulsification/internal gelation process, alginate solution with an insoluble calcium salt is added into the oil to form w/o emulsion, and then the emulsion is acidified to release $\mathrm{Ca}^{2+}$ from the insoluble salt for cross-linking with alginate. ${ }^{139}$ Song et al prepared alginate-chitosan microcapsules containing yeast cells (Y235) via emulsification/external gelation and emulsification/internal gelation and found that microencapsulated probiotics by the emulsification/internal gelation had higher viability than those obtained by the emulsification/external gelation. $^{140}$

The emulsification technique can be also used in combination with other encapsulation methods including spraydrying and extrusion to increase the survival of probiotics. $^{141,142}$ A double emulsion such as water in oil in water $(\mathrm{w} / \mathrm{o} / \mathrm{w})$ emulsion or solid in oil in water $(\mathrm{s} / \mathrm{o} / \mathrm{w})$ emulsion can also be used to improve the resistance of probiotics against the detrimental environment. PimentelGonza'leza et al encapsulated L. rhamnosus using the double-emulsion technique (w/o/w) with concentrated sweet whey as an emulsifier, demonstrating that the double emulsion was effective in improving the GI stability of probiotics. ${ }^{143}$ Recently, Zhang et al also encapsulated probiotics in emulsion droplets with multiple lipid-proteinpectin layers. ${ }^{144}$ The suspension of spray-dried L. salivarius NRL B-30514 in melted anhydrous milk fat was emulsified in a neutral aqueous phase with whey protein isolate or sodium caseinate to prepare $\mathrm{s} / \mathrm{o} / \mathrm{w}$ emulsions. Then, pectin was electrostatically deposited onto the surface of droplets at $\mathrm{pH}$ 3.0. They demonstrated successfully that this s/o/w emulsion system could improve the viability of probiotics during processing, storage, and gastrointestinal digestion. ${ }^{144}$

Given that the emulsification technique is beneficial for improving the cell viability, efforts to apply this technique in large-scale production are ongoing.

\section{Coacervation}

Coacervation represents a physicochemical approach for the preparation of polymeric microcapsules. ${ }^{145,146}$ It involves the phase separation of one or multiple hydrocolloids, through dehydration of a liquid phase. In this process, probiotics are entrapped in the solid particles or oil droplets that can be coated and eventually hardened into microcapsules. ${ }^{146,147}$ There are two methods: simple or complex coacervation. ${ }^{146,147}$ Simple coacervation is based on the salting-out of polymers by the addition of salts or polar solvents that have a higher affinity to water than the polymers. In complex coacervation, electrostatic interactions between two oppositely charged polymers lead to the separation of a biopolymer-rich phase (complex coacervates) and the formation of solid particles or liquid droplets (Figure 2). ${ }^{148}$ Complex coacervation is suitable for the microencapsulation

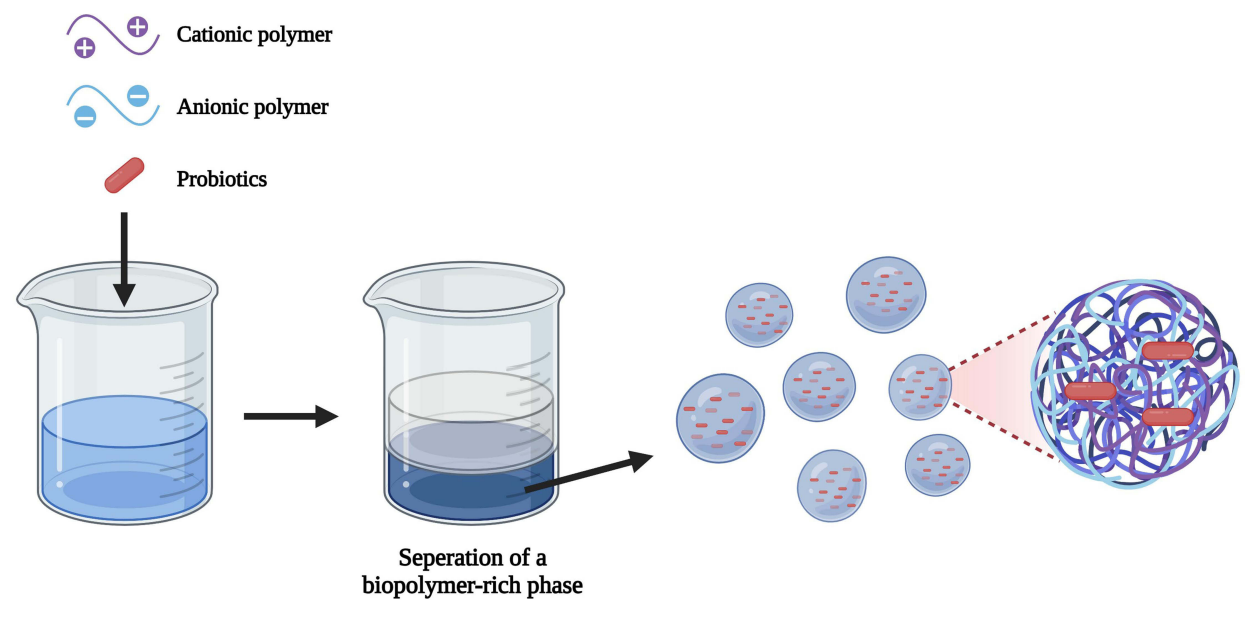

Figure 2 Complex coacervation method for encapsulation of probiotics. 
of probiotics. Oliveira et al prepared microcapsules containing probiotics by complex coacervation using a casein/pectin combination as the wall material. ${ }^{149}$ The microencapsulated probiotics were more resistant against acidic conditions than free probiotic cells. ${ }^{149}$ Zhao et al encapsulated probiotic L. reuteri by heteroprotein complex coacervation (type-A gelatin/sodium caseinate, $\mathrm{GE} / \mathrm{Cas}$ ) and compared its protective effect to that of protein/polysaccharide complex coacervation (type-A gelatin/gum arabic, GE/GA) as well as microcapsules prepared from Cas or GE only. ${ }^{150} \mathrm{GE} / \mathrm{Cas}$ coacervation was effective in improving the cell viability during storage and provide better protection of probiotics than protein/polysaccharide complex coacervation. ${ }^{150}$

Microencapsulation by coacervation exhibits many advantages including low cost, high loading capacity, capability for controlled release of probiotics by environmental stimuli (mechanical stress, temperature, and $\mathrm{pH}$ change), and avoidance of high temperature or organic solvents. ${ }^{150}$ However, since it is a batch process producing coacervates in an aqueous solution, an additional drying process is required to extend the shelf-life of the product.

\section{Nanotechnology for Probiotics}

With advances in nanotechnology, nanomaterials have been widely used for formulation since they have useful physicochemical properties including biocompatibility and the capability to respond to environmental stimuli for controlled drug release. Particularly, some nanomaterials-based formulations such as nanofibers, nanoparticles, and nanocomposites exhibit many advantages as delivery systems for viable probiotics, which include efficient encapsulation, sitespecific delivery, controlled release, and improved stability of bacterial cells during manufacturing, storage, and in vivo applications. ${ }^{151}$ Therefore, selected examples of nanomaterials-based formulations applicable for probiotics are briefly discussed in the following sections.

\section{Nanofibers}

Nanofibers are produced by an electrospinning of polymer solutions under strong electric fields. ${ }^{152}$ Natural polymers have better biocompatibility and lower immunogenicity but it is easier to modify synthetic polymers to obtain the desired physicochemical properties; therefore, polymer blends are commonly used. ${ }^{152}$ Polyvinyl alcohol, polyethylene oxide, cellulose, and chitosan are the most commonly used polymers for incorporating probiotic bacteria. ${ }^{152}$

Nanofibers exhibit uniform morphology and composition, nanometric diameter, large surface areas, and high porosity, offering many advantages for the efficient delivery of biological substances. ${ }^{153}$ Consequently, nanofibers can be used to encapsulate various microorganisms, cells, genes, and proteins. ${ }^{152,153}$ The incorporation of probiotics into nanofibers can improve the stability of probiotic bacterial cells and also allow their site-specific delivery. López-Rubio et al prepared ultrathin PVA-based electrospun fibers encapsulating Bifidobacterium animalis Bb12 (Figure 3), ${ }^{154}$ which had a mean diameter of $150 \mathrm{~nm}$ and were effective in retaining the viability of encapsulated probiotics for 40 days of storage at room temperature and for 130 days under the refrigerated conditions. ${ }^{154}$

Silva et al also fabricated PVA-nanofibers containing L. rhamnosus CRL1332, which had a mean diameter of 95 $\mathrm{nm}$ and maintained the viability of the probiotic bacteria over 360 days of oxygen-excluding storage at $4{ }^{\circ} \mathrm{C} .{ }^{153}$ Furthermore, nanofiber-immobilized $L$. rhamnosus cells retained their inhibitory effect against urogenital pathogens. ${ }^{153}$ Hirsch et al

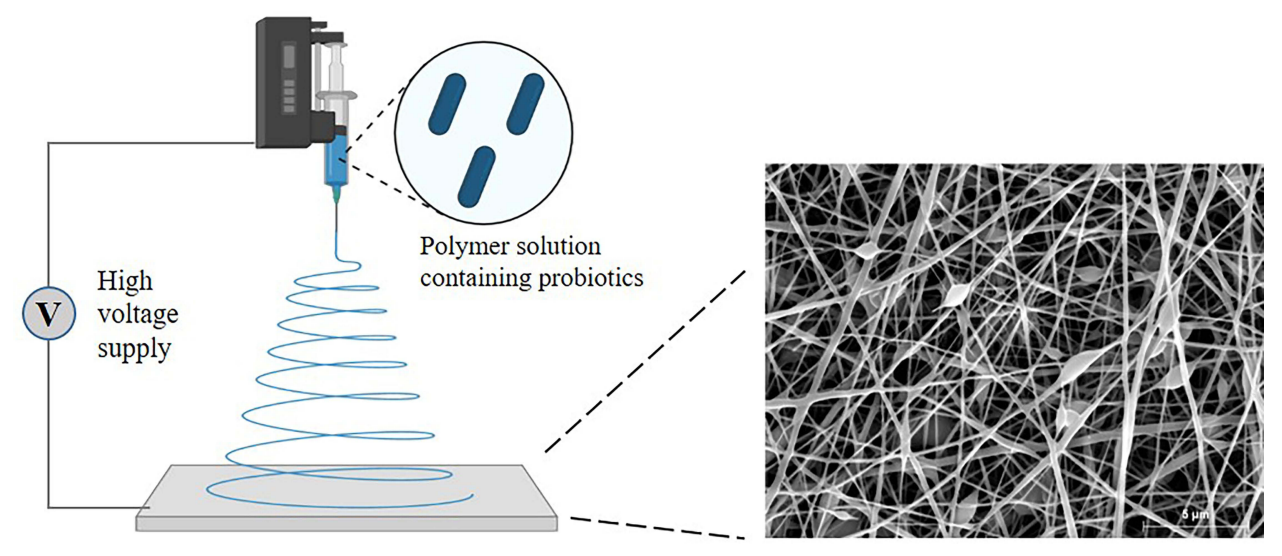

Figure 3 Illustration of electrospun nanofibers containing probiotics. Figures were partly adapted with permission from López-Rubio A, Sanchez E, Sanz Y, Lagaron JM. Encapsulation of living bifidobacteria in ultrathin PVOH electrospun fibers. Biomacromolecules. 2009;10(10):2823-2829. Copyright @ 2009 , American Chemical Society. ${ }^{154}$ 
encapsulated $L$. paracasei into PVA-polyethylene oxide (PEO) nanofibers using the high-speed electrospinning method. ${ }^{155}$ To minimize the loss of viability of $L$. paracasei, they prepared PVA-PEO fibers using various stabilizing excipients. ${ }^{155}$ Among the tested stabilizing agents, skim milk was the most effective in decreasing osmotic and dehydration stress, leading to the enhanced survival rate and long-term stability of L. paracasei. They suggested the importance of selecting the appropriate excipients during electrospinning. ${ }^{155}$

\section{Nanoparticles}

Active ingredients can be encapsulated in nanocontainers to address various issues related to stability, solubility, safety, and target specificity. ${ }^{156}$ Accordingly, probiotics can be formulated as polymeric nanoparticles, lipid-based nanoparticles, and inorganic nanoparticles. ${ }^{156}$ In recent years, hybrid nanoparticles using two different materials (eg organic/inorganic, lipid/ polymer nanoparticles) have been actively pursued to combine the advantages of each single system. Furthermore, the surface of nanoparticles can be decorated with ligands or functional materials for the targeted delivery or stimuli-responsive controlled release of probiotics. ${ }^{157}$ These nanoparticles-based drug delivery systems can protect the probiotics from harsh environments, increase the residence time at the target site, and enhance the bioavailability of probiotics. ${ }^{157}$ Ebrahimnejad et al fabricated chitosan nanoparticles loaded with Lactobacillus acidophilus that had a particle size of $146 \mathrm{~nm}$ and significantly improved viability in simulated gastric and intestinal fluids. ${ }^{158}$ Ghibaudo et al also developed iron-pectin nanoparticles loaded with L. plantarum CIDCA 83114 with enhanced stability during freeze drying and storage. ${ }^{159}$ Moreover, these nanoparticles protected the entrapped probiotics against the gastric acidity. ${ }^{159}$

\section{Nanostructured Material-Based Formulations}

Many nanomaterials with different sizes, shapes, textures, and compositions have been investigated for the effective encapsulation of probiotics. Because of their unique physical and chemical properties, nanostructured material-based formulations appear to be promising methods to improve the resistance of probiotics against detrimental environments. In recent years, hydrogels and nanomaterials have been combined to prepare nanocomposite systems that have the advantages of small size, ability to form a stable complex, high drug loading, reduced toxicity, and improved mechanical strength. ${ }^{160}$ Patarroyo et al developed gelatin-graphene oxide nanocomposite hydrogels with larger pore sizes favorable for the entrapment and proliferation of Kluyveromyces lactis. ${ }^{161}$ Nanocomposite hydrogels also exhibited $\mathrm{pH}$-dependent swelling ratio, tunable degradation rates, and high mechanical stability and integrity in simulated gastrointestinal fluids and during bioprocessing. ${ }^{161}$ Zhang et al fabricated sodium alginate/cellulose nanofiber gel macrospheres (ACMs) by extruding a mixture of sodium alginate and 2,2,6,6,-tetramethyl-1-piperidinyloxy radical (TEMPO)-oxidized cellulose nanofiber into $\mathrm{CaCl}_{2}$ solutions for cross-linking, where L. plantarum was incorporated as the probiotic bacteria. ${ }^{162}$ Since ACMs shrank in the simulated gastric fluids, the penetration of gastric acid into the ACMs was low, thereby protecting the encapsulated probiotics from the acidic environment. In contrast, ACMs dissolved rapidly in the simulated intestinal fluids, exhibiting a $\mathrm{pH}$-dependent release of the encapsulated probiotic bacteria. ${ }^{162}$ Thus, $\mathrm{pH}$ responsive gel macrospheres fabricated using a combination of sodium alginate and cellulose nanofibers are promising for the targeted delivery of probiotics to the intestine. ${ }^{162} \mathrm{Li}$ et al also prepared regenerated cellulose microgels having an interpenetrating porous structure, an improved probiotic loading capacity, and high stability. ${ }^{163}$ The microgels contained an interconnected network of cellulose nanofibrils, and the houselike structure increased the probiotic-loading capacity. In addition, after encapsulating L. plantarum, the microgels were coated with Ca-alginate to form a core-shell structure that prevented the release of the probiotic in the stomach and protected it from the harsh gastric environment but released the probiotic in the intestine. ${ }^{163}$ Thus, $\mathrm{pH}-$-responsive composite core-shell gels are useful for achieving the controlled release of probiotics and also for increasing the loading capacity. ${ }^{163}$

\section{Summary and Future Perspectives}

The stabilization of probiotics against detrimental factors is critical to promote their clinical application as therapeutic adjuvants. Therefore, various formulation approaches are actively pursued targeting different routes of administration to improve the effectiveness of probiotics as summarized in Figure 4. While conventional formulation approaches for probiotics focus on their stabilization against the harsh environment, recent advancements in formulation technology allow more elaborated delivery systems with controlled release of probiotics. Particularly, advancements in microencapsulation and nanotechnology facilitate the formulation development for optimized site-selective delivery of probiotics. In addition, probiotic dosage 


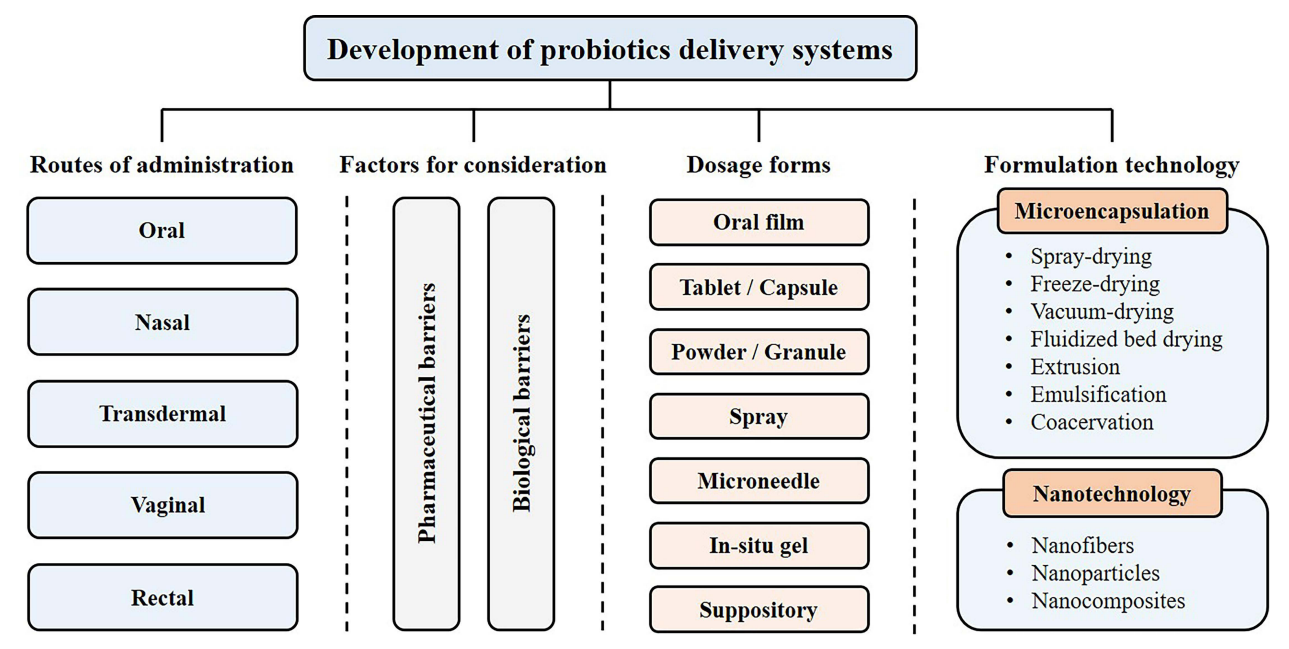

Figure 4 Formulation approaches for the pharmaceutical applications of probiotics.

forms and routes of administration can be more diversified with advancements in formulation technology and biomaterials, although oral dosage forms are predominant at present. Given that formulation processes may inactivate probiotics and alter their functionality, it is important to select suitable formulation techniques and manufacturing processes. Dehydration processes such as spray-drying, freeze-drying, and fluidized bed drying are common practice during the production of probiotics. Freeze-drying may be advantageous for reducing thermal stress while spray-drying may be more cost-effective with higher throughput. Since each formulation technique has its own advantages and limitations, the method selection depends on multiple factors including probiotic strain, size of dosage forms, route of administration, and production scale. The combined use of formulation strategies with bioengineered probiotic strains or advanced medical devices may also help enhance the effectiveness of probiotics.

Taken together, effective delivery systems for therapeutic probiotics are expected to evolve through advances in bioengineering, formulation technology, and materials science, opening a new platform for the sophisticated and precise delivery of probiotics.

\section{Acknowledgments}

This research was supported by National Research Foundation of Korea (NRF) grant funded by the Korea government (MSIT) (Nos. 2019R1A2C2004873 and 2018R1A5A2023127) and the BK21 FOUR program through NRF funded by the Ministry of Education of Korea.

\section{Disclosure}

The authors declare that they have no known competing financial interests or personal relationships that could have appeared to influence the work reported in this paper.

\section{References}

1. Singh B, Mal G, Marotta F. Designer probiotics: paving the way to living therapeutics. Trends Biotechnol. 2017;35(8):679-682. doi:10.1016/j.tibtech.2017.04.001

2. DeGruttola AK, Low D, Mizoguchi A, Mizoguchi E. Current understanding of dysbiosis in disease in human and animal models. Inflamm Bowel Dis. 2016;22(5):1137-1150. doi:10.1097/MIB.0000000000000750

3. Trush EA, Poluektova EA, Beniashvilli AG, Shifrin OS, Poluektov YM, Ivashkin VT. The evolution of human probiotics: challenges and prospects. Probiotics Antimicrob Proteins. 2020;12(4):1291-1299. doi:10.1007/s12602-019-09628-4

4. Malaguarnera G, Leggio F, Vacante M, et al. Probiotics in the gastrointestinal diseases of the elderly. $J$ Nutr Health Aging. 2012;16(4):402-410. doi:10.1007/s12603-011-0357-1

5. Doron S, Gorbach SL. Probiotics: their role in the treatment and prevention of disease. Expert Review Anti Infect Ther. 2006;4 (2):261-275. doi:10.1586/14787210.4.2.261

6. Monteagudo-Mera A, Rastall RA, Gibson GR, Charalampopoulos D, Chatzifragkou A. Adhesion mechanisms mediated by probiotics and prebiotics and their potential impact on human health. Appl Microbiol Biotechnol. 2019;103 (16):6463-6472. doi:10.1007/s00253-019-09978-7

7. Sanders ME, Merenstein DJ, Reid G, Gibson GR, Rastall RA. Probiotics and prebiotics in intestinal health and disease: from biology to the clinic. Nat Rev Gastroenterol Hepatol. 2019;16 (10):605-616. doi:10.1038/s41575-019-0173-3

8. Vandenplas Y, Huys G, Daube G. Probiotics: an update. J Pediatr. 2015;91(1):6-21. doi:10.1016/j.jped.2014.08.005

9. Cordaillat-Simmons M, Rouanet A, Pot B. Live biotherapeutic products: the importance of a defined regulatory framework. Exp Mol Med. 2020;52(9):1397-1406. doi:10.1038/s12276-020-0437-6

10. Dreher-Lesnick SM, Stibitz S, Carlson PE. U.S. regulatory considerations for development of live biotherapeutic products as drugs. Microbiol Spectr. 2017;5(5). doi:10.1128/microbiolspec. BAD-0017-2017 
11. Rodrigues D, Sousa S, Rocha-Santos T, et al. Influence of 1-cysteine, oxygen and relative humidity upon survival throughout storage of probiotic bacteria in whey protein-based microcapsules. Int Dairy J. 2011;21(11):869-876. doi:10.1016/j.idairyj.2011.05.005

12. Kim J, Muhammad N, Jhun BH, Yoo J-W. Probiotic delivery systems: a brief overview. $J$ Pharm Investig. 2016;46 (4):377-386. doi:10.1007/s40005-016-0259-7

13. Amund OD. Exploring the relationship between exposure to technological and gastrointestinal stress and probiotic functional properties of lactobacilli and bifidobacteria. Can J Microbiol. 2016;62(9):715-725. doi:10.1139/cjm-2016-0186

14. Lee SH, Bajracharya R, Min JY, Han JW, Park BJ, Han HK. Strategic approaches for colon targeted drug delivery: an overview of recent advancements. Pharmaceutics. 2020;12(1):68.

15. Yao M, Xie J, Du H, McClements DJ, Xiao H, Li L. Progress in microencapsulation of probiotics: a review. Compre Rev Food Sci. 2020;19(2):857-874. doi:10.1111/1541-4337.12532

16. Urdaneta V, Casadesús J. Interactions between bacteria and bile salts in the gastrointestinal and hepatobiliary tracts. Front Med. 2017;4:163. doi:10.3389/fmed.2017.00163

17. Grenier D. Effect of proteolytic enzymes on the lysis and growth of oral bacteria. Oral Microbiol Immunol. 1994;9(4):224-228. doi:10.1111/j.1399-302X.1994.tb00062.x

18. Pliszczak D, Bourgeois S, Bordes C, et al. Improvement of an encapsulation process for the preparation of pro- and prebiotics-loaded bioadhesive microparticles by using experimental design. Eur J Pharm Sci. 2011;44(1):83-92. doi:10.1016/j.ejps.2011.06.011

19. Merkus FW, Verhoef JC, Schipper NG, Marttin E. Nasal mucociliary clearance as a factor in nasal drug delivery. Adv Drug Deliv Rev. 1998;29(1-2):13-38. doi:10.1016/S0169-409X(97)00059-8

20. Serralheiro A, Alves G, Sousa J, Fortuna A, Falcão A. Nose as a route for drug delivery. In: Önerci TM, editor. Nasal Physiology and Pathophysiology of Nasal Disorders. 1st ed. Berlin: Springer; 2013:191-215.

21. De Rudder C, Garcia-Tímermans C, De Boeck I, Lebeer S, Van de Wiele T, Calatayud Arroyo M. Lacticaseibacillus casei AMBR2 modulates the epithelial barrier function and immune response in a donor-derived nasal microbiota manner. Sci Rep. 2020;10(1):16939. doi:10.1038/s41598-020-73857-9

22. Terpou A, Papadaki A, Lappa IK, Kachrimanidou V, Bosnea LA, Kopsahelis N. Probiotics in food systems: significance and emerging strategies towards improved viability and delivery of enhanced beneficial value. Nutrients. 2019;11(7):1591. doi:10.3390/nu11071591

23. Stanbury PF, Whitaker A, Hall SJ. The recovery and purification of fermentation products. In: Stanbury PF, Whitaker A, Hall SJ, editors. Principles of Fermentation Technology. 3rd ed. Oxford: Butterworth-Heinemann; 2017:619-686.

24. Blair TC, Buckton G, Bloomfield SF. On the mechanism of kill of microbial contaminants during tablet compression. Int J Pharm. 1991;72(2):111-115. doi:10.1016/0378-5173(91)90048-S

25. Plumpton EJ, Gilbert P, Fell JT. The survival of microorganisms during tabletting. Int $J$ Pharm. 1986;30(2-3):241-246. doi:10.1016/0378-5173(86)90086-4

26. Mills S, Stanton C, Fitzgerald GF, Ross RP. Enhancing the stress responses of probiotics for a lifestyle from gut to product and back again. Microb Cell Fact. 2011;10(Suppl 1):S19-S19. doi:10.1186/1475-2859-10-S1-S19

27. Baez A, Shiloach J. Effect of elevated oxygen concentration on bacteria, yeasts, and cells propagated for production of biological compounds. Microb Cell Fact. 2014;13:181. doi:10.1186/s12934014-0181-5

28. Teruel AH, Gonzalez-Alvarez I, Bermejo M, et al. New insights of oral colonic drug delivery systems for inflammatory bowel disease therapy. Int J Mol Sci. 2020;21(18):6502. doi:10.3390/ ijms21186502
29. Pech-Canul AD, Ortega D, García-Triana A, González-Silva N, Solis-Oviedo RL. A brief review of edible coating materials for the microencapsulation of probiotics. Coatings. 2020;10(3):197. doi:10.3390/coatings 10030197

30. Kim W-S, Cho C-S, Hong L, et al. Oral delivery of probiotics using pH-sensitive phthalyl inulin tablets. J Microbiol Biotechnol. 2019;29(2):200-208. doi:10.4014/jmb.1811.11021

31. Irfan M, Rabel S, Bukhtar Q, Qadir MI, Jabeen F, Khan A. Orally disintegrating films: a modern expansion in drug delivery system. Saudi Pharm J. 2016;24(5):537-546. doi:10.1016/j.jsps.2015.02.024

32. Lee Y, Kim K, Kim M, Choi DH, Jeong SH. Orally disintegrating films focusing on formulation, manufacturing process, and characterization. $J$ Pharm Investig. 2017;47(3):183-201. doi:10.1007/s40005-017-0311-2

33. Hoffmann EM, Breitenbach A, Breitkreutz J. Advances in orodispersible films for drug delivery. Expert Opin Drug Deliv. 2011;8(3):299-316. doi:10.1517/17425247.2011.553217

34. Heinemann RJB, Carvalho RA, Favaro-Trindade CS. Orally disintegrating film (ODF) for delivery of probiotics in the oral cavity -development of a novel product for oral health. Innov Food Sci Emerg Technol. 2013;19:227-232. doi:10.1016/j.ifset.2013.0 4.009

35. Lordello VB, Meneguin AB, de Annunzio SR, et al. Orodispersible film loaded with enterococcus faecium CRL183 presents anti-candida albicans biofilm activity in vitro. Pharmaceutics. 2021;13(7):998. doi:10.3390/pharmaceutics1 3070998

36. Dodoo CC, Stapleton P, Basit AW, Gaisford S. The potential of Streptococcus salivarius oral films in the management of dental caries: an inkjet printing approach. Int $J$ Pharm. 2020;591:119962. doi:10.1016/j.ijpharm.2020.119962

37. Abruzzo A, Vitali B, Lombardi F, et al. Mucoadhesive buccal films for local delivery of Lactobacillus brevis. Pharmaceutics. 2020;12(3):241. doi:10.3390/pharmaceutics12030241

38. Barbosa de Souza Ferreira S, Fukase GO, Gomes RG, Bruschi ML. Mucoadhesive wafers for buccal delivery of probiotic bacteria: mechanical properties and enumeration. J Drug Deliv Sci Technol. 2021;61(102201):102201.

39. Capela P, Hay TKC, Shah NP. Effect of cryoprotectants, prebiotics and microencapsulation on survival of probiotic organisms in yoghurt and freeze-dried yoghurt. Food Res Int. 2006;39 (2):203-211. doi:10.1016/j.foodres.2005.07.007

40. Her J-Y, Song C-S, Lee SJ, Lee K-G. Preparation of kanamycin powder by an optimized spray freeze-drying method. Powder Technol. 2010;199(2):159-164. doi:10.1016/j.powtec.2009.1 2.018

41. Lian W-C, Hsiao H-C, Chou -C-C. Survival of bifidobacteria after spray-drying. Int $J$ Food Microbiol. 2002;74(1):79-86. doi:10.1016/S0168-1605(01)00733-4

42. Her J-Y, Kim MS, Lee K-G. Preparation of probiotic powder by the spray freeze-drying method. J Food Eng. 2015;150:70-74. doi:10.1016/j.jfoodeng.2014.10.029

43. Iaconelli C, Lemetais G, Kechaou N, et al. Drying process strongly affects probiotics viability and functionalities. J Biotechnol. 2015;214:17-26. doi:10.1016/j.jbiotec.2015.08.022

44. Shanmugam S. Granulation techniques and technologies: recent progresses. Bioimpacts. 2015;5(1):55-63. doi:10.15171/bi.20 15.04

45. Pyar H, Peh KK. Enteric coating of granules containing the probiotic Lactobacillus acidophilus. Acta Pharm. 2014;64 (2):247-256. doi:10.2478/acph-2014-0011

46. Aponte M, Ungaro F, d'Angelo I, et al. Improving in vivo conversion of oleuropein into hydroxytyrosol by oral granules containing probiotic Lactobacillus plantarum $299 \mathrm{v}$ and an Olea europaea standardized extract. Int $J$ Pharm. 2018;543(12):73-82. doi:10.1016/j.ijpharm.2018.03.013 
47. Kim YI, Poudel BK, Pradhan R, et al. Development of a novel bi-coated combination capsule containing mosapride and probiotics for irritable bowel syndrome. Pharma Dev Technol. 2015;20 (8):949-956. doi:10.3109/10837450.2014.954723

48. Dodoo CC, Wang J, Basit AW, Stapleton P, Gaisford S. Targeted delivery of probiotics to enhance gastrointestinal stability and intestinal colonisation. Int J Pharm. 2017;530(1-2):224-229. doi:10.1016/j.ijpharm.2017.07.068

49. Ibekwe VC, Khela MK, Evans DF, Basit AW. A new concept in colonic drug targeting: a combined $\mathrm{pH}$-responsive and bacterially-triggered drug delivery technology. Aliment Pharmacol Ther. 2008;28(7):911-916. doi:10.1111/j.13652036.2008.03810.x

50. Yucel Falco C, Sotres J, Rascón A, Risbo J, Cárdenas M. Design of a potentially prebiotic and responsive encapsulation material for probiotic bacteria based on chitosan and sulfated $\beta$-glucan. $J$ Colloid Interface. 2017;487:97-106. doi:10.1016/j.jcis.20 16.10 .019

51. Hoffmann A, Fischer JT, Daniels R. Development of probiotic orodispersible tablets using mucoadhesive polymers for buccal mucoadhesion. Drug Dev Ind Pharm. 2020;46(11):1753-1762. doi:10.1080/03639045.2020.1831013

52. Khodaverdi E, Maftouhian S, Aliabadi A, et al. Casein-based hydrogel carrying insulin: preparation, in vitro evaluation and in vivo assessment. J Pharm Investig. 2019;49(6):635-641. doi:10.1007/s40005-018-00422-y

53. Sacco P, Paoletti S, Cok M, et al. Insight into the ionotropic gelation of chitosan using tripolyphosphate and pyrophosphate as cross-linkers. Int $J$ Biol Macromol. 2016;92:476-483. doi:10.1016/j.ijbiomac.2016.07.056

54. Kwiecień I, Kwiecień M. Application of polysaccharide-based hydrogels as probiotic delivery systems. Gels. 2018;4(2):47. doi: $10.3390 /$ gels4020047

55. Liu H, Xie M, Nie S. Recent trends and applications of polysaccharides for microencapsulation of probiotics. Food Front. 2020;1(1):45-59. doi:10.1002/fft2.11

56. Dafe A, Etemadi H, Dilmaghani A, Mahdavinia GR. Investigation of pectin/starch hydrogel as a carrier for oral delivery of probiotic bacteria. Int J Biol Macromol. 2017;97:536-543. doi:10.1016/j.ijbiomac.2017.01.060

57. Cook MT, Tzortzis G, Khutoryanskiy VV, Charalampopoulos D. Layer-by-layer coating of alginate matrices with chitosan-alginate for the improved survival and targeted delivery of probiotic bacteria after oral administration. J Mater Chem B. 2013;1 (1):52-60. doi:10.1039/C2TB00126H

58. Bashir S, Hina M, Iqbal J, et al. Fundamental concepts of hydrogels: synthesis, properties, and their applications. Polymers. 2020;12(11):2702. doi:10.3390/polym 12112702

59. Reddy MSB, Ponnamma D, Choudhary R, Sadasivuni KK. A comparative review of natural and synthetic biopolymer composite scaffolds. Polymers. 2021;13(7):1105. doi:10.3390/ polym13071105

60. Kumar AC, Erothu H. Synthetic polymer hydrogels. In: Francis R, Kumar DS, editors. Biomedical Applications of Polymeric Materials and Composites. Weinheim: Wiley; 2016:141-162.

61. Ragupathy S, Esmaeili F, Paschoud S, Sublet E, Citi S, Borchard G. Toll-like receptor 2 regulates the barrier function of human bronchial epithelial monolayers through atypical protein kinase $\mathrm{C}$ zeta, and an increase in expression of claudin-1. Tissue Barriers. 2014;2(2):e29166. doi:10.4161/tisb.29166

62. Martens K, Pugin B, De Boeck I, et al. Probiotics for the airways: potential to improve epithelial and immune homeostasis. Allergy. 2018;73(10):1954-1963. doi:10.1111/all.13495

63. Kitazawa H, Villena J, Alvarez S. Probiotics: Immunobiotics and Immunogenics. CRC Press; 2013.
64. Kim JY, Park MS, Ji GE. Probiotic modulation of dendritic cells co-cultured with intestinal epithelial cells. World J Gastroenterol. 2012;18(12):1308-1318. doi:10.3748/wjg.v18.i12.1308

65. Xu J, Tao J, Wang J. Design and application in delivery system of intranasal antidepressants. Front Bioeng Biotechnol. 2020;8 (1450):626882. doi:10.3389/fbioe.2020.626882

66. Erdő F, Bors LA, Farkas D, Bajza Á, Gizurarson S. Evaluation of intranasal delivery route of drug administration for brain targeting. Brain Res Bull. 2018;143:155-170. doi:10.1016/j. brainresbull.2018.10.009

67. Chaturvedi M, Kumar M, Pathak K. A review on mucoadhesive polymer used in nasal drug delivery system. J Adv Pharm Technol Res. 2011;2(4):215-222. doi:10.4103/2231-4040.90876

68. Marchisio P, Santagati M, Scillato M, et al. Streptococcus salivarius $24 \mathrm{SMB}$ administered by nasal spray for the prevention of acute otitis media in otitis-prone children. Eur J Clin Microbiol Infect Dis. 2015;34(12):2377-2383. doi:10.1007/s10096-0152491-x

69. Cantarutti A, Rea F, Donà $\mathrm{D}$, et al. Preventing recurrent acute otitis media with Streptococcus salivarius 24SMB and Streptococcus oralis 89 a five months intermittent treatment: an observational prospective cohort study. Int $J$ of Pediatr Otorhinolaryngol. 2020;132:109921. doi:10.1016/j.ijporl.202 0.109921

70. La Mantia I, Varricchio A, Ciprandi G. Bacteriotherapy with Streptococcus salivarius 24SMB and Streptococcus oralis $89 \mathrm{a}$ nasal spray for preventing recurrent acute otitis media in children: a real-life clinical experience. Int J Gen Med. 2017;10:171-175. doi:10.2147/IJGM.S137614

71. Jokicevic K, Kiekens S, Byl E, et al. Probiotic nasal spray development by spray drying. Eur $J$ Pharm Biopharm. 2021;159:211-220. doi:10.1016/j.ejpb.2020.11.008

72. Ammar HO, Mohamed MI, Tadros MI, Fouly AA. High frequency ultrasound mediated transdermal delivery of ondansetron hydrochloride employing bilosomal gel systems: ex-vivo and in-vivo characterization studies. J Pharm Investig. 2020;50 (6):613-624. doi:10.1007/s40005-020-00491-y

73. Byrd AL, Belkaid Y, Segre JA. The human skin microbiome. Nat Rev Microbiol. 2018;16(3):143-155. doi:10.1038/nrmicro.20 17.157

74. Proksch E. pH in nature, humans and skin. J Dermatol. 2018;45 (9):1044-1052. doi:10.1111/1346-8138.14489

75. Cinque B, La Torre C, Melchiorre E, et al. Use of probiotics for dermal applications. In: Liong MT, editor. Probiotics. Berlin: Springer; 2011:221-241.

76. Finnin BC, Morgan TM. Transdermal penetration enhancers: applications, limitations, and potential. J Pharm Sci. 1999;88 (10):955-958. doi:10.1021/js990154g

77. Akhtar N, Singh V, Yusuf M, Khan RA. Non-invasive drug delivery technology: development and current status of transdermal drug delivery devices, techniques and biomedical applications. Biomed Eng. 2020;65(3):243-272.

78. Larrañeta E, Lutton REM, Woolfson AD, Donnelly RF. Microneedle arrays as transdermal and intradermal drug delivery systems: materials science, manufacture and commercial development. Mater Sci Eng $R$ Rep. 2016;104:1-32. doi:10.1016/j.mser.2016.03.001

79. Cho lee A-R. Microneedle-mediated delivery of cosmeceutically relevant nucleoside and peptides in human skin: challenges and strategies for dermal delivery. J Pharm Investig. 2019;49 (6):587-601. doi:10.1007/s40005-019-00438-y

80. Donnelly RF, Raj Singh TR, Woolfson AD. Microneedle-based drug delivery systems: microfabrication, drug delivery, and safety. Drug Deliv. 2010;17(4):187-207. doi:10.3109/10717541 003667798 
81. Waghule T, Singhvi G, Dubey SK, et al. Microneedles: a smart approach and increasing potential for transdermal drug delivery system. Biomedicine \& Pharmacotherapy. 2019;109:1249-1258. doi:10.1016/j.biopha.2018.10.078

82. Chen H-J, Lin D-A, Liu F, et al. Transdermal delivery of living and biofunctional probiotics through dissolvable microneedle patches. ACS Applied Biomater. 2018;1(2):374-381. doi:10.1021/acsabm.8b00102

83. van de Wijgert J, Verwijs MC. Lactobacilli-containing vaginal probiotics to cure or prevent bacterial or fungal vaginal dysbiosis: a systematic review and recommendations for future trial designs. BJOG. 2020;127(2):287-299. doi:10.1111/1471-0528.15870

84. Ma L, Su J, Su Y, Sun W, Zeng Z. Probiotics administered intravaginally as a complementary therapy combined with antibiotics for the treatment of bacterial vaginosis: a systematic review protocol. BMJ Open. 2017;7(10):e019301. doi:10.1136/ bmjopen-2017-019301

85. Kim JM, Park YJ. Probiotics in the prevention and treatment of postmenopausal vaginal infections: review article. J Menopausal Med. 2017;23(3):139-145. doi:10.6118/jmm.2017.23.3.139

86. Reid G, Charbonneau D, Erb J, et al. Oral use of Lactobacillus rhamnosus GR-1 and L. fermentum RC-14 significantly alters vaginal flora: randomized, placebo-controlled trial in 64 healthy women. FEMS Immunol Med Microbiol. 2003;35(2):131-134. doi:10.1016/S0928-8244(02)00465-0

87. Sarwal A, Singh G, Singh S, Singh K, Sinha VR. Novel and effectual delivery of an antifungal agent for the treatment of persistent vulvovaginal candidiasis. J Pharm Investig. 2019;49 (1):135-147. doi:10.1007/s40005-018-0395-3

88. Sánchez MT, Ruiz MA, Castán H, Morales ME. A novel double-layer mucoadhesive tablet containing probiotic strain for vaginal administration: design, development and technological evaluation. Eur J Pharm Sci. 2018;112:63-70. doi:10.1016/j. ejps.2017.11.006

89. Palmeira-de-oliveira R, Palmeira-de-oliveira A, Martinez-deoliveira J. New strategies for local treatment of vaginal infections. Adv Drug Deliv Rev. 2015;92:105-122. doi:10.1016/ j.addr.2015.06.008

90. Vigani B, Faccendini A, Rossi S, et al. Development of a mucoadhesive in situ gelling formulation for the delivery of Lactobacillus gasseri into vaginal cavity. Pharmaceutics. 2019;11 (10):511. doi:10.3390/pharmaceutics11100511

91. Vigani B, Rossi S, Sandri G, Bonferino MC, Caramella MC, Ferrari F. Recent advances in the development of in situ gelling drug delivery systems for non-parenteral administration routes. Pharmaceutics. 2020;12(9):859. doi:10.3390/pharmaceutics12090859

92. Fakhari A, Corcoran M, Schwarz A. Thermogelling properties of purified poloxamer 407. Heliyon. 2017;3(8):e00390. doi:10.1016/ j.heliyon.2017.e00390

93. Caramella CM, Rossi S, Ferrari F, Bonferoni MC, Sandri G. Mucoadhesive and thermogelling systems for vaginal drug delivery. Adv Drug Deliv Rev. 2015;92:39-52. doi:10.1016/j. addr.2015.02.001

94. Garg S, Goldman D, Krumme M, Rohan LC, Smoot S, Friend DR. Advances in development, scale-up and manufacturing of microbicide gels, films, and tablets. Antiviral Res. 2010;88: S19-S29. doi:10.1016/j.antiviral.2010.09.010

95. Vicariotto F, Mogna L, Del Piano M. Effectiveness of the two microorganisms Lactobacillus fermentum LF15 and Lactobacillus plantarum LP01, formulated in slow-release vaginal tablets, in women affected by bacterial vaginosis: a pilot study. J Clin Gastroenterol. 2014;48:S106-S112. doi:10.1097/MCG.0000000000000226

96. Maggi L, Mastromarino P, Macchia S, et al. Technological and biological evaluation of tablets containing different strains of lactobacilli for vaginal administration. Eur J Pharm Biopharm. 2000;50(3):389-395. doi:10.1016/S0939-6411(00)00121-1
97. Mastromarino P, Macchia S, Meggiorini L, et al. Effectiveness of Lactobacillus-containing vaginal tablets in the treatment of symptomatic bacterial vaginosis. Clin Microbiol Infect. 2009;15 (1):67-74. doi:10.1111/j.1469-0691.2008.02112.x

98. Ham AS, Buckheit RW. Designing and developing suppository formulations for anti-HIV drug delivery. Ther Deliv. 2017;8 (9):805-817. doi:10.4155/tde-2017-0056

99. Haas S, Woerdenbag H, Sznitowska M. Rectal and vaginal. In: Bouwman-Boer Y, Fenton-May V, Le Brun P, editors. Practical Pharmaceutics. New York: Springer; 2015:189-227.

100. Darwish AM, Farah E, Gadallah WA, Mohammad II. Superiority of newly developed vaginal suppositories over vaginal use of commercial bromocriptine tablets: a randomized controlled clinical trial. Reprod Sci. 2007;14(3):280-285. doi:10.1177/ 1933719107301056

101. Rodrigues F, Maia MJ, Das Neves J, Sarmento B, Amaral MH, Oliveira MB. Vaginal suppositories containing Lactobacillus acidophilus: development and characterization. Drug Dev Ind Pharm. 2015;41(9):1518-1525. doi:10.3109/03639045.2014.963864

102. Camilletti AL, Ruiz FO, Pascual LM, Barberis IL. First steps towards the pharmaceutical development of ovules containing Lactobacillus strains: viability and antimicrobial activity as basic first parameters in vaginal formulations. AAPS PharmSciTech. 2018;19(2):886-895. doi:10.1208/s12249-0170895-x

103. Kale VV, Trivedi RV, Wate SP, Bhusari KP. Development and evaluation of a suppository formulation containing Lactobacillus and its application in vaginal diseases. Ann N Y Acad Sci. 2005;1056:359-365. doi:10.1196/annals.1352.017

104. Verdenelli MC, Coman MM, Cecchini C, Silvi S, Orpianesi C, Cresci A. Evaluation of antipathogenic activity and adherence properties of human Lactobacillus strains for vaginal formulations. J Appl Microbiol. 2014;116(5):1297-1307. doi:10.1 111/jam. 12459

105. Ghouri YA, Richards DM, Rahimi EF, Krill JT, Jelinek KA, DuPont AW. Systematic review of randomized controlled trials of probiotics, prebiotics, and synbiotics in inflammatory bowel disease. Clin Exp Gastroenterol. 2014;7:473-487.

106. Rioux KP, Fedorak RN. Probiotics in the treatment of inflammatory bowel disease. J Clin Gastroenterol. 2006;40(3):260-263. doi:10.1097/00004836-200603000-00019

107. Heselmans M, Reid G, Akkermans LM, Savelkoul H, Timmerman H, Rombouts FM. Gut flora in health and disease: potential role of probiotics. Curr Issues Intest Microbiol. 2005;6 (1):1-7.

108. Guarner F, Malagelada JR. Gut flora in health and disease. Lancet. 2003;361(9356):512-519. doi:10.1016/S0140-6736(03) $12489-0$

109. D'Incà R, Barollo $M$, Scarpa $M$, et al. Rectal administration of Lactobacillus casei DG modifies flora composition and Toll-like receptor expression in colonic mucosa of patients with mild ulcerative colitis. Dig Dis Sci. 2011;56(4):1178-1187. doi:10.1007/s10620-010-1384-1

110. Amit-Romach E, Uni Z, Friedman M, Aizenberg I, Berkovich Z, Reifen R. A new mode of probiotic therapy: specific targeting. J Funct Foods. 2015;16:386-392. doi:10.1016/j.jff.2015.04.029

111. Oliva S, Di Nardo G, Ferrari F, et al. Randomised clinical trial: the effectiveness of Lactobacillus reuteri ATCC 55730 rectal enema in children with active distal ulcerative colitis. Aliment Pharmacol Ther. 2012;35(3):327-334. doi:10.1111/j.13652036.2011.04939.x

112. Šipailienè A, Petraitytè S. Encapsulation of probiotics: proper selection of the probiotic strain and the influence of encapsulation technology and materials on the viability of encapsulated microorganisms. Probiotics Antimicrob Proteins. 2018;10 (1):1-10. doi:10.1007/s12602-017-9347-x 
113. Chávarri M, Marañón I, Villarán MC. Encapsulation technology to protect probiotic bacteria. In: Rigobeleo EC, editor. Probiotics. London: IntechOpen; 2012.

114. Fazilah NF, Hamidon NH, Ariff AB, Khayat ME, Wasoh H, Halim M. Microencapsulation of Lactococcus lactis Gh1 with gum arabic and synsepalum dulcificum via spray drying for potential inclusion in functional yogurt. Molecules. 2019;24 (7):1422. doi:10.3390/molecules24071422

115. Zheng X, Fu N, Duan M, Woo MW, Selomulya C, Chen XD. The mechanisms of the protective effects of reconstituted skim milk during convective droplet drying of lactic acid bacteria. Food Res Int. 2015;76(Pt 3):478-488. doi:10.1016/j.foodres.2015.07.045

116. Khem S, Woo MW, Small DM, Chen XD, May BK. Agent selection and protective effects during single droplet drying of bacteria. Food Chem. 2015;166:206-214. doi:10.1016/j. foodchem.2014.06.010

117. e Silva JPS, Sousa SC, Costa P, et al. Development of probiotic tablets using microparticles: viability studies and stability studies. AAPS PharmSciTech. 2013;14(1):121-127. doi:10.1208/s12249012-9898-9

118. Perdana J, Bereschenko L, Fox MB, et al. Dehydration and thermal inactivation of Lactobacillus plantarum WCFS1: comparing single droplet drying to spray and freeze drying. Food Res Int. 2013;54(2):1351-1359. doi:10.1016/j.foodres.2013.09.043

119. Ré I. Microencapsulation by spray drying. Dry Technol. 1998;16 (6):1195-1236. doi:10.1080/07373939808917460

120. Goderska K. Different methods of probiotics stabilization. In: Rigobelo EC, editor. Probiotics. London: IntechOpen; 2012.

121. Farahmandi K, Rajab S, Tabandeh F, Shahraky MK, Maghsoudi A, Ashengroph M. Efficient spray-drying of Lactobacillus rhamnosus PTCC 1637 using total CFU yield as the decision factor. Food Biosci. 2021;40:100816. doi:10.1016/j. fbio.2020.100816

122. Strasser S, Neureiter M, Geppl M, Braun R, Danner H. Influence of lyophilization, fluidized bed drying, addition of protectants, and storage on the viability of lactic acid bacteria. J Appl Microbiol. 2009;107 (1):167-177. doi:10.1111/j.1365-2672.2009.04192.x

123. Fowler A, Toner M. Cryo-injury and biopreservation. Ann N Y Acad Sci. 2005;1066:119-135. doi:10.1196/annals.1363.010

124. Smirnoff N, Cumbes QJ. Hydroxyl radical scavenging activity of compatible solutes. Phytochemistry. 1989;28(4):1057-1060. doi:10.1016/0031-9422(89)80182-7

125. Coulibaly I, Dubois-Dauphin R, Destain J, Fauconnier M-L, Lognay $G$, Thonart $P$. The resistance to freeze-drying and to storage was determined as the cellular ability to recover its survival rate and acidification activity. Int $J$ Microbiol. 2010;2010:625239. doi:10.1155/2010/625239

126. Champagne CP, Mondou F, Raymond Y, Roy D. Effect of polymers and storage temperature on the stability of freeze-dried lactic acid bacteria. Food Res Int. 1996;29(5):555-562. doi:10.1016/0963-9969(95)00050-X

127. Broeckx G, Vandenheuvel D, Claes IJJ, Lebeer S, Kiekens F. Drying techniques of probiotic bacteria as an important step towards the development of novel pharmabiotics. Int J Pharm. 2016;505(1):303-318. doi:10.1016/j.ijpharm.2016.04.002

128. Martín MJ, Lara-Villoslada F, Ruiz MA, Morales ME Microencapsulation of bacteria: a review of different technologies and their impact on the probiotic effects. Innov Food Sci Emerg Technol. 2015;27:15-25. doi:10.1016/j.ifset.2014.09.010

129. Santivarangkna C, Kulozik U, Foerst P. Alternative drying processes for the industrial preservation of lactic acid starter cultures. Biotechnol Prog. 2007;23(2):302-315. doi:10.1021/bp060268f

130. Zaghari L, Basiri A, Rahimi S. Preparation and characterization of double-coated probiotic bacteria via a fluid-bed process: a case study on Lactobacillus reuteri. Int J Food Eng. 2020;16(9). doi:10.1515/ijfe-2019-0384
131. Wu W-H, Roe WS, Gimino VG, Seriburi V, Martin DE, Knapp SE. Low melt encapsulation with high laurate canola oil. United States Patent US 6153256; 2000.

132. Burgain J, Gaiani C, Linder M, Scher J. Encapsulation of probiotic living cells: from laboratory scale to industrial applications. J Food Eng. 2011;104(4):467-483. doi:10.1016/j.jfoodeng.2010.12.031

133. Rokka S, Rantamäki P. Protecting probiotic bacteria by microencapsulation: challenges for industrial applications. Eur Food Res Technol. 2010;231(1):1-12. doi:10.1007/s00217-010-1246-2

134. Lee Y, Ji YR, Lee S, Choi MJ, Cho Y. Microencapsulation of probiotic Lactobacillus acidophilus KBL409 by extrusion technology to enhance survival under simulated intestinal and freeze-drying conditions. J Microbiol Biotechnol. 2019;29 (5):721-730. doi:10.4014/jmb.1903.03018

135. Shah NP, Ravula RR. Microencapsulation of probiotic bacteria and their survival in frozen fermented desserts. Aust J Dairy Technol. 2000;55:139-144.

136. Krasaekoopt W, Bhandari B, Deeth H. Evaluation of encapsulation techniques of probiotics for yoghurt. Int Dairy J. 2003;13 (1):3-13. doi:10.1016/S0958-6946(02)00155-3

137. Hou RC, Lin MY, Wang MM, Tzen JT. Increase of viability of entrapped cells of Lactobacillus delbrueckii ssp. bulgaricus in artificial sesame oil emulsions. $J$ Dairy Sci. 2003;86 (2):424-428. doi:10.3168/jds.S0022-0302(03)73620-0

138. Qi W, Liang X, Yun T, Guo W. Growth and survival of microencapsulated probiotics prepared by emulsion and internal gelation. $J$ Food Sci Technol. 2019;56(3):1398-1404. doi:10.1007/s13197-019-03616-w

139. Poncelet D, Lencki R, Beaulieu C, Halle JP, Neufeld RJ, Fournier A. Production of alginate beads by emulsification/internal gelation. I. Methodology. Appl Microbiol Biotechnol. 1992;38 (1):39-45. doi:10.1007/BF00169416

140. Song H, Yu W, Gao M, Liu X, Ma X. Microencapsulated probiotics using emulsification technique coupled with internal or external gelation process. Carbohydr Polym. 2013;96(1):181-189. doi:10.1016/j.carbpol.2013.03.068

141. Crittenden R, Weerakkody R, Sanguansri L, Augustin M. Synbiotic microcapsules that enhance microbial viability during nonrefrigerated storage and gastrointestinal transit. Appl Environ Microbiol. 2006;72(3):2280-2282. doi:10.1128/AEM.72.3.22802282.2006

142. Özer B, Kirmaci HA, Şenel E, Atamer M, Hayaloğlu A. Improving the viability of Bifidobacterium bifidum BB-12 and Lactobacillus acidophilus LA-5 in white-brined cheese by microencapsulation. Int Dairy J. 2009;19(1):22-29. doi:10.1016/ j.idairyj.2008.07.001

143. Pimentel-González DJ, Campos-Montiel RG, Lobato-Calleros C, Pedroza-Islas R, Vernon-Carter EJ. Encapsulation of Lactobacillus rhamnosus in double emulsions formulated with sweet whey as emulsifier and survival in simulated gastrointestinal conditions. Food Res Int. 2009;42(2):292-297. doi:10.1016/j. foodres.2008.12.002

144. Zhang Y, Lin J, Zhong Q. The increased viability of probiotic Lactobacillus salivarius NRRL B-30514 encapsulated in emulsions with multiple lipid-protein-pectin layers. Food Res Int. 2015;71:9-15. doi:10.1016/j.foodres.2015.02.017

145. de Kruif CG, Weinbreck F, de Vries R. Complex coacervation of proteins and anionic polysaccharides. Curr Opin Colloid Interface Sci. 2004;9(5):340-349. doi:10.1016/j.cocis.2004.09.006

146. Goin S. Microencapsulation: industrial appraisal of existing technologies. Food Sci Technol. 2004;15:330-347. doi:10.1016/ j.tifs.2003.10.005

147. Bosnea LA, Moschakis T, Biliaderis CG. Complex coacervation as a novel microencapsulation technique to improve viability of probiotics under different stresses. Food Bioprocess Technol. 2014;7(10):2767-2781. doi:10.1007/s11947-014-1317-7 
148. Schmitt C, Sanchez C, Desobry-Banon S, Hardy J. Structure and technofunctional properties of protein-polysaccharide complexes: a review. Crit Rev Food Sci Nutr. 1998;38(8):689-753. doi:10.1080/10408699891274354

149. Oliveira AC, Moretti TS, Boschini C, Baliero JC, Freitas O, Favaro-Trindade CS. Stability of microencapsulated B. lactis (BI 01) and L. acidophilus (LAC 4) by complex coacervation followed by spray drying. J Microencapsul. 2007;24(7):673-681. doi:10.1080/02652040701532908

150. Zhao M, Huang $\mathrm{X}$, Zhang $\mathrm{H}$, et al. Probiotic encapsulation in water-in-water emulsion via heteroprotein complex coacervation of type-A gelatin/sodium caseinate. Food Hydrocoll. 2020;105:105790. doi:10.1016/j.foodhyd.2020.105790

151. Razavi S, Janfaza S, Tasnim N, Gibson DL, Hoorfar M. Nanomaterial-based encapsulation for controlled gastrointestinal delivery of viable probiotic bacteria. Nanoscale Adv. 2021;3 (10):2699-2709. doi:10.1039/D0NA00952K

152. Stojanov S, Berlec A. Electrospun nanofibers as carriers of microorganisms, stem cells, proteins, and nucleic acids in therapeutic and other applications. Front Bioeng Biotechnol. 2020;8:130. doi:10.3389/fbioe. 2020.00130

153. Silva JA, De Gregorio PR, Rivero G, Abraham GA, NaderMacías MEF. Immobilization of vaginal Lactobacillus in polymeric nanofibers for its incorporation in vaginal probiotic products. Eur J Pharm Sci. 2021;156:105563. doi:10.1016/j. ejps.2020.105563

154. López-Rubio A, Sanchez E, Sanz Y, Lagaron JM. Encapsulation of living bifidobacteria in ultrathin $\mathrm{PVOH}$ electrospun fibers. Biomacromolecules. 2009;10(10):2823-2829. doi:10.1021/ bm900660b

155. Hirsch E, Pantea E, Vass P, et al. Probiotic bacteria stabilized in orally dissolving nanofibers prepared by high-speed electrospinning. Food Bioprod Process. 2021;128:84-94. doi:10.1016/j.fbp.2021.04.016
156. Yang J, Jia C, Yang J. Designing nanoparticle-based drug delivery systems for precision medicine. Int J Med Sci. 2021;18 (13):2943-2949. doi:10.7150/ijms.60874

157. Kashapov R, Ibragimova A, Pavlov R, et al. Nanocarriers for biomedicine: from lipid formulations to inorganic and hybrid nanoparticles. Int J Mol Sci. 2021;22(13):7055. doi:10.3390/ ijms22137055

158. Ebrahimnezhad P, Khavarpour M, Khalili S. Survival of Lactobacillus acidophilus as probiotic bacteria using chitosan nanoparticles. Int J Eng. 2017;30(4):456-463.

159. Ghibaudo F, Gerbino E, Copello GJ, Campo Dall' Orto V, Gómez-Zavaglia A. Pectin-decorated magnetite nanoparticles as both iron delivery systems and protective matrices for probiotic bacteria. Colloids Surf B Biointerfaces. 2019;180:193-201. doi:10.1016/j.colsurfb.2019.04.049

160. Andretto V, Rosso A, Briançon S, Lollo G. Nanocomposite systems for precise oral delivery of drugs and biologics. Drug Deliv Transl Res. 2021;11(2):445-470. doi:10.1007/s13346021-00905-w

161. Patarroyo JL, Fonseca E, Cifuentes J, Salcedo F, Cruz JC, Reyes LH. Gelatin-graphene oxide nanocomposite hydrogels for kluyveromyces lactis encapsulation: potential applications in probiotics and bioreactor packings. Biomolecules. 2021;11(7):922. doi:10.3390/biom11070922

162. Zhang $\mathrm{H}$, Yang $\mathrm{C}$, Zhou W, et al. A pH-responsive gel macrosphere based on sodium alginate and cellulose nanofiber for potential intestinal delivery of probiotics. ACS Sustain Chem Eng. 2018;6(11):13924-13931. doi:10.1021/acssuscheme ng. 8 b02237

163. Li W, Zhu Y, Ye F, Li B, Luo X, Liu S. Probiotics in cellulose houses: enhanced viability and targeted delivery of Lactobacillus plantarum. Food Hydrocoll. 2017;62:66-72. doi:10.1016/j. foodhyd.2016.07.019
International Journal of Nanomedicine

\section{Publish your work in this journal}

The International Journal of Nanomedicine is an international, peerreviewed journal focusing on the application of nanotechnology in diagnostics, therapeutics, and drug delivery systems throughout the biomedical field. This journal is indexed on PubMed Central, MedLine, CAS, SciSearch ${ }^{\mathbb{}}$, Current Contents ${ }^{\mathbb{R}} /$ Clinical Medicine,

\section{Dovepress}

Journal Citation Reports/Science Edition, EMBase, Scopus and the Elsevier Bibliographic databases. The manuscript management system is completely online and includes a very quick and fair peer-review system, which is all easy to use. Visit http://www.dovepress.com/ testimonials.php to read real quotes from published authors. 